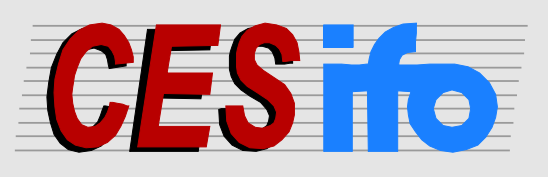

\title{
Working
}

Papers

www.cesifo.org/wp

\section{Strategic Choices for Redistribution and the Veil of Ignorance: Theory and Experimental Evidence}

\author{
Anke Gerber \\ Andreas Nicklisch \\ Stefan Voigt
}

CESIFO WORKING PAPER NO. 4423

CATEGORY 13: BEHAVIOURAL ECONOMICS

OCTOBER 2013

An electronic version of the paper may be downloaded

- from the SSRN website:

- from the RePEc website:

- from the CESifo website:

WwW.SSRN.com

www.RePEc.org

www.CESifo-group.org/wp

\section{CESifo}




\title{
Strategic Choices for Redistribution and the Veil of Ignorance: Theory and Experimental Evidence
}

\begin{abstract}
We provide experimental evidence on the emergence of redistributive societies. Individuals first vote on redistribution by feet and then learn their productivity and invest. We vary the individuals' information about their productivities at the time when they choose a distribution rule and find that there is more redistribution behind a veil of ignorance than under full information. However, the scope of redistribution is less sensitive towards the degree of uncertainty than predicted. For all degrees of uncertainty, we find a coexistence of libertarianism and redistribution as well as incomplete sorting, so that heterogeneous redistribution communities turn out to be sustainable.
\end{abstract}

JEL-Code: C910, D020, D630, H240, K000.

Keywords: constitutional choice, experimental economics, redistribution, veil of ignorance, voting by feet.

\author{
Anke Gerber* \\ Department of Economics \\ University of Hamburg \\ Von-Melle-Park 5 \\ Germany - 20146 Hamburg \\ anke.gerber@wiso.uni-hamburg.de
}

\author{
Andreas Nicklisch \\ Department of Economics \\ University of Hamburg \\ Von-Melle-Park 5 \\ Germany - 20146 Hamburg \\ andreas.nicklisch@wiso.uni-hamburg.de
}

\author{
Stefan Voigt \\ Institute of Law \& Economics \\ University of Hamburg \\ Johnsallee 35 \\ Germany - 20148 Hamburg \\ stefan.voigt@uni-hamburg.de
}

*corresponding author

October 2, 2013

The authors thank seminar audiences at the Universitat Autònoma de Barcelona, University of Bayreuth, Maastricht University, Universitat Rovira i Virgili, Seoul National University and, in particular, Jörg Franke, Kai Konrad, Stefan Napel, Arno Riedl and Peter Wakker for useful comments. Financial support by the University of Hamburg, and research assistance by Dominik Hattrup are gratefully acknowledged. 


\section{Introduction}

Rawls (1971) famously draws on a veil of ignorance to derive his principles of justice. The central idea is that when people choosing a constitution are deprived of all sorts of information (regarding their age, gender, productive capacities, social status, etc.) they have an incentive to agree on fair and just rules. To protect themselves against the vicissitudes of life, people would consent to a high degree of redistribution that is to improve the lot of the worst off (the famous difference principle). Buchanan and Tullock (1962) rely on a very similar idea: in their setting, people know who they are today, but are uncertain of their future selves. Within this frame, higher degrees of uncertainty do not only lead to the installment of a distributive state but also to a higher likelihood to agree on constitutional rules unanimously. This paper tackles the question whether it is indeed true that the scope of redistribution increases with the degree of uncertainty and whether there is indeed less plurality in individuals' preferences for different distribution rules under higher degrees of uncertainty.

Unlike Rawls (1971) who used the veil as a hypothetical device to justify his justice principle, ${ }^{1}$ we consider in our analysis real decisions for a certain type of welfare system. Hence, we model the choice of a (re-)distribution principle as a strategic game played simultaneously by all members of society behind a veil of ignorance. As such, decisions behind the the veil not only reflect individual preferences but also expected choices by other subjects. As a consequence, we analyze in our paper the strategic institutional choice for or against redistribution, while we vary the thickness of the veil.

For this purpose, we study a setting where individuals vote by feet when they choose a distribution rule. This environment mimics the migration of a population with - depending on the thickness of the veil - (ex-ante) homogeneous or heterogeneous productivity types between different communities (cf. Tiebout, 1956). It allows for several parallel societies which are subject to different redistribution rules. While this voting by feet procedure has been successfully applied for the analysis of social dilemmas (e.g., Gürerk et al., 2006; Rockenbach and

\footnotetext{
${ }^{1}$ Rawls (1971, p. 137) points out that the notion of the veil is "so natural a condition that something like it must have occurred to many." In fact, Harsanyi (1953) and, even earlier, Vickrey (1945) have already used a hypothetical veil of ignorance to point to the similarity between individual choices under risk and society's choice of an income distribution.
} 
Milinski, 2006), it also introduces an interesting new strategic element into the choice of a distribution rule since specific types may gather under specific rules. Under voting by feet the relevance of the individual choice is somewhere in the middle between the two alternative institutions, namely majority voting, where the individual choice has only a marginal effect, and dictatorship, where it is pivotal. We consider our setting as a meaningful model not only within the Tiebout framework, but also with regard to contemporary migration movements, where millions of migrants regularly relocate across nations (prominent examples are migration waves from Latin America to the US, or from Southern to Northern Europe). Institutional preferences may be one of the reasons for or against specific countries (Kauppinen and Poutvaara, 2012), while the value of migrants' homeland qualifications is subject to a substantial uncertainty.

We first analyze our model theoretically, and then run a laboratory experiment to test the theoretical predictions. To keep the analysis tractable without losing too much generality, we focus on three prominent redistribution principles: the egalitarian rule (where total income is shared equally), the libertarian rule (where everyone keeps their income) and the proportional rule (where total income is shared in proportion to the individual investments; cf. Sen, 1966). In the experiment, subjects repeatedly vote by feet with individual productivities drawn anew in every round according to the same distribution which is common knowledge. Treatments differ with respect to the information subjects have about their own productivities at the time when they choose their redistribution principle. Thereafter, their individual productivity is fully revealed, and they set their production which is then divided according to the distribution rule.

Our main results are the following: the theoretical prediction that there is more redistribution under higher degrees of uncertainty is only partially confirmed by our experiment. There is indeed significantly more redistribution under no information than under full or partial information. However, relative to the theoretical benchmark, subjects in the experiment choose too little redistribution under no information and too much under partial information, so that overall there is no significant difference between partial and no information with respect to the size of redistributive societies. Moreover, while theoretically a coexistence of libertarian and redistributive societies is obtained only under partial information, in the experiment we see parallel societies relying on different 
redistribution rules under all informational scenarios. This is also in contrast to the prediction put forward by Buchanan and Tullock (1962), that we should expect more unanimous consent on one constitutional rule under higher degrees of uncertainty. Finally, different from the theoretical prediction, redistributive societies in the experiment are not necessarily segregated. We explain the experimental results by biased expectations about the future productivity: subjects in our experiment behave as if they form expectations relative to their current productivity rather than absolute expectations as a Bayesian would do. Thus, we identify the anticipated social mobility as a crucial factor for the emergence of redistributive societies.

Our paper relates to different strands of the literature. One is the literature that tries to elicit people's preferences for different distributive principles. Frohlich et al. (1987) let subjects choose from among four principles behind a veil of ignorance, namely (1) maximize the floor income (Rawls' difference principle), (2) maximize the average income, (3) maximize the average income with a floor constraint, and (4) maximize the average income with a range constraint. $^{2}$ Frohlich and Oppenheimer (1990) introduce a consecutive production phase whose nature is not known to the subjects when they choose the distribution principle. They find almost no support for egalitarianism, that is, the difference principle, while the endogenous choice of the principle increased productivity significantly. Our paper extends Frohlich and Oppenheimer, as players in our model have complete information about all details of the production stage before choosing a distribution rule, which renders the institutional choice a strategic decision that is not affected by ambiguity about the nature of the production stage. Cappelen et al. (2007) present results from a dictator game where a production phase is followed by a redistribution phase. Each player's contribution is the consequence of an individually chosen investment level and an exogenously determined rate of return. They observe considerable pluralism in fairness ide-

\footnotetext{
${ }^{2}$ Early experimental results for (non-strategic) decisions behind the veil of ignorance are provided by Yaari and Bar-Hillel (1984), while a number of other studies followed this tradition (e.g., Andersson and Lyttkens, 1999; Johansson-Stenman et al., 2002; Carlsson et al., 2003). Related to this, several authors analyze how negotiation partners and third parties redistribute surplus varying individual effort (e.g., Schokkaert and Capeau, 1989; Schokkaert and Capeau, 1991; Konow, 2000), their risk taking (Cappelen et al., 2013; Riedl and Cettolin, 2013) or trading off efficiency and equality (e.g., Faravelli, 2007; for a survey of the literature see Tausch et al., 2013).
} 
als. Different from Cappelen et al. (2007) we consider a situation where the institutional choice takes place before all uncertainty about productivities and investments is resolved. This is, of course, the central feature of the veil and the way most constitutional economists have thought about constitutional choice. ${ }^{3}$

Moreover, our paper is related to the political economy literature on the puzzle of the very different sizes of the welfare state, and hence redistribution, on the two sides of the Atlantic. It is a well-known stylized fact that the U.S. has a very small welfare state whereas continental (particularly Northern) Europe has many full-blown welfare states with substantial redistribution. One important determinant for the difference in size are differences in basic constitutional rules as a consequence of different constitutional choices (e.g., Corneo and Grüner, 2002; Alesina and Glaeser, 2004; Alesina and Fuchs-Schündeln, 2007). Along this line, Buchanan and Tullock (1962) sketch a research program that is interested in identifying the determinants of constitutional choice and change (Hayo and Voigt, 2013, provide a survey of this literature). In their seminal article, Meltzer and Richard (1981) identify the ratio of the mean income in society to the income of the median voter as a key element determining the size of redistribution. Experimental studies by Konrad and Morath (2010, 2011) show that along this ratio income mobility crucially influences the desired amount of redistribution. Using laboratory experiments with large groups, Durante and Putterman (2009) compare subjects' demand for redistribution once they are directly affected and once they are unaffected third parties. Between treatment conditions, the authors vary the deadweight loss associated with redistribution ("taxation costs"). The majority of subjects prefers less inequality once they are third parties, and respond strongly to changes to the cost of taxation. ${ }^{4}$ Finally, Großer and Reuben (2013) question whether the scope of redistribution and the way the scope is chosen influence the efficiency of an upfront production phase. They find that full redistribution reduces trading efficiency substantially, while imposing this redistribution rate exogenously, or letting subjects vote for this rate does affect this

\footnotetext{
${ }^{3}$ One exception is Ticchi and Vindigni (2010) who draw on Beard (1913) and argue that empirically, the veil does not play any role at all which is why the authors refrain from any attempts to incorporate any veil-like notions into their model.

${ }^{4}$ Supporting the findings by Durante and Putterman (2009), Tyran and Sausgruber (2005) show that fairness considerations matter substantially for the voting behavior on redistribution, whereas Rutström and Williams (2000) find that voting is predominantly driven by narrow selfinterest.
} 
result.

Cabrales et al. (2012) conduct an experiment with costly production, followed by majority voting on egalitarian redistribution. They find that redistribution in conjunction with high effort is not sustainable because the rich are never willing to reward the poor even if they have put in high effort in the production phase. In a recent paper, Barberà et al. (2013) study the core of a coalition formation game, where players first form a coalition and then every coalition has a majority vote on its distribution principle, which can be either meritocratic (no redistribution) or egalitarian. Hence, different from our model the players do not select themselves into a priori given distribution rules but rather choose the distribution principle ex post, after coalitions have been formed and the productivities of all coalition members are known. Moreover, players do not invest in this model. That is, the effect of different distribution principles on players' investment incentives and economic efficiency is not considered. Nonetheless, findings are similar to our results: different distribution principles coexist, while stable coalition structures may include non-segregated groups.

The rest of the paper is structured as follows: In Section 2, we present our model and the theoretical predictions. In Section 3 we describe the experimental design. In Section 4 the experimental results are presented and discussed. Section 5 concludes.

\section{The Model}

There are $n$ individuals who are homogeneous with respect to their endowment $w>0$ but heterogeneous with respect to their productivities. Individual $i$ 's productivity $r_{i}>1$ is her gross return on investment in an individual project: if individual $i$ invests $q_{i} \in[0, w]$, her project generates income $r_{i} q_{i}$. The investment $q_{i}$ can be interpreted as labor time or effort, in which case $r_{i} q_{i}$ is individual $i$ 's wage income. Every individual $i$ has an expected utility function with a von Neumann-Morgenstern utility function $u_{i}$ that is increasing and concave in the monetary payoff.

We consider a two-stage game, where in stage 1 all individuals simultaneously choose a distribution rule and in stage 2 all individuals simultaneously 
choose their investments in the individual projects. The group of individuals who have chosen the same distribution rule share the total income from the individual projects according to the distribution rule. We will solve for the subgame perfect Nash equilibria of the two-stage game under different assumptions about the individuals' information concerning their own productivity in stage 1. In stage 2 individuals are always assumed to have complete information about the productivities of all group members.

In the following let $S$ be the set of individuals who have chosen the specific rule under consideration and let $|S|$ denote the number of individuals in $S$. We consider the following rules which represent three prominent distribution principles:

\section{Rule L (Libertarianism)}

Under this rule there is no redistribution and every individual keeps her income. Hence, if $i$ has chosen rule $L$ in stage 1 , then $i$ 's payoff is

$$
\pi_{i}^{L}=w-q_{i}+r_{i} q_{i}
$$

independent of the income generated by the other individuals who have chosen

rule $L$. Since $r_{i}>1$, under rule $L$ it is a dominant strategy for individual $i$ to invest $q_{i}^{*}=w$ in stage 2 of the game.

\section{Rule E (Egalitarianism)}

Under this rule the total income from the individual projects is shared equally among the individuals in $S$, irrespective of whether potential income inequalities are the result of individual investment decisions or are due to heterogeneous productivities which are beyond the individuals' control. Thus, the egalitarian rule is a welfaristic version of Rawls' (1971) difference principle.

Under rule $E$ the payoff of individual $i \in S$ is

$$
\pi_{i}^{E}=w-q_{i}+\frac{1}{|S|} \sum_{j \in S} r_{j} q_{j}
$$


Hence, in stage 2 it is a dominant strategy for individual $i \in S$ to invest

$$
q_{i}^{*}=\left\{\begin{array}{ll}
w & \text {, if } r_{i}>|S| \\
0 \quad & \text { if } r_{i}<|S| \\
q \in[0, w] & \text { if } r_{i}=|S|
\end{array} .\right.
$$

\section{Rule P (Proportionality)}

Under this rule the total income from the individual projects is shared proportionally to the investments of the individuals in $S$. Hence, all remaining inequalities in payoffs are the result of differences in individual investment decisions. Proportionality is a common principle used to solve all kinds of distribution problems, such as bankruptcy problems or cost-sharing problems. The proportional rule also formalizes the socialist principle "to each according to his work" (Marx, 1933).

The payoff of individual $i \in S$ then is

$$
\pi_{i}^{P}=w-q_{i}+\frac{q_{i}}{\sum_{j \in S} q_{j}} \sum_{j \in S} r_{j} q_{j} .
$$

It is straightforward to show that $\pi_{i}^{P}$ is strictly increasing in $q_{i}$ for all $\left(q_{j}\right)_{j \neq i}$. Hence, it is a dominant strategy for individual $i$ to invest $q_{i}^{*}=w$ in stage 2 of the game.

The three rules introduced above represent two extreme notions of distributional justice and one compromise between the extremes: the libertarian rule holds everyone responsible both for the individual productivity as well as for the investment decision. Under the egalitarian rule individuals are neither held responsible for their individual productivity nor for their investment decisions. Finally, the proportional rule is a compromise, where individuals are only held responsible for what is under their control, namely their investment decisions.

For our analysis of stage 1 of the game we assume that individual productiv-

\footnotetext{
${ }^{5}$ See also Sen (1966), who studied the welfare implications of a proportional distribution rule in a cooperative.
} 
ities are identically and independently distributed (i.i.d.) on a finite support

$$
\mathcal{R}=\left\{r^{1}, r^{2}, \ldots, r^{M}\right\}
$$

where $1<r^{1}<r^{2}<\ldots<r^{M}$. Individuals simultaneously choose a distribution rule from the set $\{L, E, P\}$. At this stage they do not have any information about the productivities of the other individuals. We then distinguish between three cases concerning the information an individual has about her own productivity in stage 1: 1. full information, which simulates a choice in front of the veil of ignorance, 2. no information, which simulates a choice behind a thick veil of ignorance, and 3. partial information, which simulates a choice behind a thin veil of ignorance. All proofs of the following results are in the Appendix A.

\section{$2.1 \quad$ Full Information}

Suppose every individual knows her own productivity $r_{i}$, but not the productivities $r_{j}$ for $j \neq i$, when choosing a distribution rule in stage 1 . In this case individual $i$ 's strategy in stage 1 is a mapping $\sigma_{i}: \mathcal{R} \rightarrow\{L, E, P\}$. By $\pi_{i}(\sigma \mid r)$ we denote individual $i$ 's payoff at the strategy profile $\sigma=\left(\sigma_{1}, \ldots, \sigma_{n}\right)$ given that $i$ has productivity $r \in \mathcal{R}$ and given that play continues with the equilibrium investment strategies in stage 2. Observe that $\pi_{i}(\sigma \mid r)$ is a random variable since the productivities $r_{j}, j \neq i$, are i.i.d. on $\mathcal{R}$. Here and in the following we shortly say that a strategy profile $\sigma^{*}$ is a Nash equilibrium if there exists a Nash equilibrium $q^{*}$ in stage 2 such that $\sigma^{*}$ together with $q^{*}$ is a subgame perfect Nash equilibrium of the game.

There always exists the trivial equilibrium $\sigma^{0}$, with $\sigma_{i}^{0}(r)=L$ for all $i$ and for all $r \in \mathcal{R}$. It turns out that all Nash equilibria must be payoff equivalent to $\sigma^{0}$, since no high productivity individual is willing to share her high income with a low productivity individual. Hence, there is no redistribution under full information:

Proposition 2.1. Under full information, $\sigma^{0}$ with $\sigma_{i}^{0}(r)=L$ for all $i$ and for all $r \in \mathcal{R}$ is a Nash equilibrium. Any Nash equilibrium $\sigma^{*}$ is payoff equivalent to $\sigma^{0}$, i.e., every individual $i$ has a riskless equilibrium payoff $\pi_{i}\left(\sigma^{*} \mid r\right)=r w$ for all 
$r \in \mathcal{R}$.

A straightforward implication of Proposition 2.1 is the following corollary:

Corollary 2.1. If $\sigma^{*}$ is a Nash equilibrium under full information, then

$$
\sigma_{i}^{*}(r) \neq P \text { for all } i \text { with } r>r^{1} \text {. }
$$

For general degrees of risk aversion there may exist Nash equilibria, where some individuals with the same productivity $r>r^{1}$ choose rule $E$. This is due to the fact that there is no investment under rule $E$ if the number of individuals choosing rule $E$ is larger than $r$. In this case, a very risk averse individual with productivity $r^{1}$ may be deterred from choosing rule $E$ even if some individuals with $r>r^{1}$ choose rule $E$. However, if $r^{1}$ is sufficiently close to 1 and if all individuals are either risk neutral or risk averse with a sufficiently weak risk aversion, then all individuals must choose rule $L$ in equilibrium, whenever their productivity is larger than $r^{1}$.

Proposition 2.2. If $r^{1}$ is sufficiently close to 1 and if all individuals are either risk neutral or risk averse with a sufficiently weak risk aversion, then $\sigma^{*}$ is a Nash equilibrium under full information if and only if

$$
\sigma_{i}^{*}(r)=L \text { for all } i \text { with } r>r^{1}
$$

and

$$
\left|\left\{i \mid \sigma_{i}^{*}\left(r^{1}\right)=E\right\}\right| \leq r^{1}
$$

Observe that the Nash equilibrium $\sigma^{0}$, where all players choose $L$ independent of their productivities, is a special case of the Nash equilibria characterized in Proposition 2.2. 


\subsection{No Information}

Suppose now that individuals neither know their own productivity nor the productivities of the other individuals when choosing the distributional rule in stage 1. In this case individual $i$ 's strategy in stage $1, \sigma_{i}$, is an element of $\{L, E, P\}$. Let $\pi_{i}(\sigma)$ be individual $i$ 's payoff at the strategy profile $\sigma$ and let

$$
S_{\Omega}(\sigma)=\left\{i \mid \sigma_{i}=\Omega\right\}
$$

denote the set of individuals choosing rule $\Omega \in\{L, E, P\}$ at the strategy profile $\sigma$.

As in the full information case, there always exists the trivial equilibrium, where all individuals choose rule $L$. Since this result is immediate, we state the following proposition without proof.

Proposition 2.3. Under no information, $\sigma^{0}$ with $\sigma_{i}^{0}=L$ for all $i$ is a Nash equilibrium.

However, different from the case of choice under full information, now there exist additional equilibria which are not payoff equivalent to $\sigma^{0}$. To see this, we first make the following observation:

Lemma 2.1. Under no information, for all $i$ and for all strategy profiles $\sigma$ with $\sigma_{i}=P$,

$$
\mathbb{E}\left[u_{i}\left(\pi_{i}(\sigma)\right)\right] \geq \mathbb{E}\left[u_{i}(r w)\right]
$$

and the inequality is strict if $\left|S_{P}(\sigma)\right| \geq 2$ and $i$ is risk averse, i.e., $u_{i}$ is strictly concave.

Lemma 2.1 implies the following result:

Proposition 2.4. Under no information, $\sigma^{*}$ with $\sigma_{i}^{*}=P$ for all $i$ is a Nash equilibrium and it is strict if all individuals are risk averse. 
It turns out that there exist additional Nash equilibria that we will characterize in the following. To this end we first observe that whenever $r^{1}<2$ and $\left|S_{E}(\sigma)\right| \geq 2$, then there is a positive probability that at least one individual will not invest under rule $E$. This implies

$$
\mathbb{E}\left[\sum_{i \in S_{E}(\sigma)} \pi_{i}(\sigma)\right]<\left|S_{E}(\sigma)\right| \mu w
$$

where $\mu=\mathbb{E}[r]$ is the expected productivity of an individual. Hence, if $r^{1}<2$ and $\left|S_{E}(\sigma)\right| \geq 2$, then there exists $i \in S_{E}(\sigma)$ with

$$
\mathbb{E}\left[\pi_{i}(\sigma)\right]<\mu w=\mathbb{E}\left[\pi_{i}\left(\bar{\sigma}_{i}, \sigma_{-i}\right)\right]
$$

for $\bar{\sigma}_{i} \in\{L, P\}$, independent of the number of individuals in $S_{L}\left(\bar{\sigma}_{i}, \sigma_{-i}\right)$ and $S_{P}\left(\bar{\sigma}_{i}, \sigma_{-i}\right)$. From (1) we get the following result:

Proposition 2.5. Under no information, if $r^{1}<2$ and if all individuals are risk neutral, that is, $u_{i}$ is linear for all $i$, then $\sigma^{*}$ is a Nash equilibrium if and only if $\left|S_{E}\left(\sigma^{*}\right)\right| \leq 1$.

If individuals are risk averse, the set of Nash equilibria is considerably smaller than under risk neutrality. The following proposition shows that under certain conditions on the possible productivities either none or all individuals must choose rule $P$ in equilibrium and there is a bound on the maximum number of individuals choosing rule $E$ :

Proposition 2.6. Suppose all individuals are risk averse, that is, $u_{i}$ is strictly concave for all $i$. If $\sigma^{*}$ is a Nash equilibrium under no information, and if $r^{1}<$ 2 and $r^{M} \leq\left\lfloor\frac{n+1}{2}\right\rfloor$, then $\left|S_{E}\left(\sigma^{*}\right)\right| \leq\left\lfloor\frac{n+1}{2}\right\rfloor .{ }^{6}$ Moreover, there exists no Nash equilibrium $\sigma^{*}$ with $1 \leq\left|S_{P}\left(\sigma^{*}\right)\right|<n$.

Under the assumptions in Proposition 2.6 it follows that apart from the equilibria, where all individuals choose $P$ or all choose $L$, the only additional equilibrium candidates are strategy profiles with $\sigma_{i}^{*} \in\{E, L\}$ for all $i$ and

\footnotetext{
${ }^{6}$ By $\lfloor x\rfloor$ we denote the largest integer $m$ with $m \leq x$ and by $\lceil x\rceil$ we denote the smallest integer $m$ with $m \geq x$.
} 
$\left|S_{E}\left(\sigma^{*}\right)\right| \leq\left\lfloor\frac{n+1}{2}\right\rfloor$. If individuals are risk averse but the risk aversion is sufficiently weak, then the set of Nash equilibria shrinks even further: In any Nash equilibrium either all individuals choose rule $P$ or no one chooses $P$ and at most one individual chooses rule $E$. While the first Nash equilibrium is efficient, the latter equilibria are inefficient and payoff equivalent to $\sigma^{0}$.

Proposition 2.7. Suppose all individuals are risk averse, that is, $u_{i}$ is strictly concave for all $i$. If $r^{1}<2$, and if the individuals' risk aversion is sufficiently weak, then $\sigma^{*}$ is a Nash equilibrium under no information if and only if either

$$
\sigma_{i}^{*}=P \text { for all } i
$$

or

$$
\sigma_{i}^{*} \neq P \text { for all } i \text { and } \sigma_{j}^{*}=E \text { for at most one } j \text {. }
$$

Observe that the Nash equilibrium $\sigma^{0}$, where all players choose $L$, is a special case of the Nash equilibria characterized in Proposition 2.7. Moreover, only the equilibrium $\sigma^{*}$ with $\sigma_{i}^{*}=P$ for all $i$ is strict.

\subsection{Partial Information}

In the following we restrict to the case where $M=3$, which is the case considered in our experiment. Under partial information, before choosing a rule, individual $i$ receives a signal $s_{i} \in\{\ell, m, h\}$ about her productivity. Individual signals are identically and independently distributed with $\operatorname{Prob}\left(s_{i}=s\right)=\frac{1}{3}$ for all $s \in$ $\{\ell, m, h\}$. Given signal $s_{i}$, the conditional probabilities for productivities $r^{1}, r^{2}$, and $r^{3}$ are as follows:

$$
\begin{aligned}
& \operatorname{Prob}\left(r_{i}=r^{1} \mid s_{i}=\ell\right)=\operatorname{Prob}\left(r_{i}=r^{2} \mid s_{i}=\ell\right)=\frac{1}{2}, \\
& \operatorname{Prob}\left(r_{i}=r^{1} \mid s_{i}=m\right)=\operatorname{Prob}\left(r_{i}=r^{3} \mid s_{i}=m\right)=\frac{1}{2}, \\
& \operatorname{Prob}\left(r_{i}=r^{2} \mid s_{i}=h\right)=\operatorname{Prob}\left(r_{i}=r^{3} \mid s_{i}=h\right)=\frac{1}{2} .
\end{aligned}
$$


Individual $i$ 's strategy then is a mapping $\sigma_{i}:\{l, m, h\} \rightarrow\{L, E, P\}$. Similar to the case of full information (cf. Corollary 2.1) we observe that no individual with signal $h$ or $m$ chooses rule $P$ in equilibrium if individuals are not too risk averse.

Lemma 2.2. Let $\sigma^{*}$ be a Nash equilibrium under partial information. If individuals are risk neutral or risk averse and if their risk aversion is sufficiently weak, then

$$
\sigma_{i}^{*}(h) \neq P \text { and } \sigma_{i}^{*}(m) \neq P \text { for all } i .
$$

If in addition we assume that $r^{3}>2$ and $r^{1}$ is close to 1 , then all individuals with signal $h$ or $m$ choose rule $L$ in equilibrium and either all individuals with signal $\ell$ choose rule $P$ or none of them chooses rule $P$ and at most one individual with signal $\ell$ chooses rule $E$ :

Proposition 2.8. Let $r^{3}>2$. If all individuals are risk averse and if their risk aversion is sufficiently weak, and if $r^{1}$ is sufficiently close to 1 , then $\sigma^{*}$ is a Nash equilibrium under partial information if and only if

$$
\sigma_{i}^{*}(h)=\sigma_{i}^{*}(m)=L \text { for all } i
$$

and either

$$
\sigma_{i}^{*}(\ell)=P \text { for all } i,
$$

or

$$
\sigma_{i}^{*}(\ell) \neq P \text { for all } i \text { and } \sigma_{j}^{*}(\ell)=E \text { for at most one } j .
$$

Observe that the Nash equilibrium, where all players choose $L$ independent of their signal, is a special case of the Nash equilibria characterized in Proposition 2.8. Also, similar to the case of no information considered before, only the equilibrium with $\sigma_{i}^{*}(\ell)=P$ for all $i$ is strict. 
Summarizing, under the assumptions of Proposition 2.8, if there is redistribution at all, then it is restricted to those individuals with a low signal, i.e., those individuals who either have productivity $r^{1}$ or $r^{2}$.

\section{Experiment}

\subsection{Experimental Design}

For the experimental implementation of our game, we let participants interact repeatedly within groups of 10 players (i.e., $n=10$ ) for 32 periods in constant group compositions (partner matching). In every period, each player receives an endowment of $w_{i}=10$ Taler, and is assigned to one of three productivity classes (i.e., $M=3$ ): $r^{1}=1.2, r^{2}=3, r^{3}=5{ }^{7}$ Hence, the net return on investment is either $20 \%, 200 \%$, or $400 \%$. The assignment is an independent random draw with equal probabilities for each of the three classes. All parameters and payoff functions of the game are common knowledge.

We test our three variations concerning the players' information about their productivities when they choose a distribution rule: under no information (NI) subjects choose a distribution rule before learning their individual productivity; under partial information (PI) subjects receive a noisy signal about their individual productivity before they choose a distribution rule; that is, they are informed about two productivities they may have with equal probability. Finally, under full information (FI) subjects learn their individual productivity before they choose a distribution rule. Notice that player $i$, after choosing her rule, receives detailed information concerning her productivity, the number of subjects who have chosen the same rule as she has, $|S|$, and the productivities of the players in her subgroup $S$. Then, $i$ determines her investment $q_{i}$. At the end of each period, participants are informed about the total income in their group, $\sum_{j \in S} r_{j} q_{j}$, and about their payoff $\pi_{i}$. In addition, from period two onward, subjects are informed about the number of subjects who have chosen rules $L, E$, and $P$, and about the average payoff obtained under all three rules in every previous period. At the

\footnotetext{
${ }^{7}$ An inspection of the proofs of the propositions in Section 2 reveals that the equilibrium characterizations hold for the productivity parameters in our experiment.
} 
end of the experiment, participants were asked to state hypothetically (and nonincentivized) their preferred distribution rule given they had to dictate a rule for the entire group (in PI and FI depending on their own signal or productivity, respectively). Moreover, they had to answer a short questionnaire concerning their socio-economic background.

Overall, we ran 6 sessions with a total of 170 participants. Within each session, we had three independent groups ${ }^{8}$ yielding 6 independent observations for NI and FI, and 5 independent observations for PI. All experimental sessions were conducted in the experimental laboratory of the School of Business, Economics and Social Sciences at the University of Hamburg, Germany, between June and August 2012. Each session lasted approximately 90 minutes. We used z-Tree (Fischbacher, 2007) to program the experiment and ORSEE (Greiner 2004) for recruiting. Each subject participated in only one treatment condition. Once all subjects were seated, written instructions were handed to them before the experimenter read them out aloud. ${ }^{9}$ Subjects were given the opportunity to ask questions (in private). Before the experiment started, subjects had to answer a set of control questions. Most participants were students (2\% non-students) with different academic backgrounds including economics, $56 \%$ were women and median age was 24 . In order to exclude "productivity hedging" between periods, one of the periods was randomly selected at the end of the experiment. Only this period determined the earnings at an exchange rate of 1 Euro for 3 Taler. Including a show-up fee of 5 Euros, the average payment over all treatments was 14.53 Euros (with a range from 6.85 Euros to 21.70 Euros).

\subsection{Hypotheses}

From our theoretical analysis we derive three central hypotheses for the case of weakly risk averse individuals. ${ }^{10}$ The first hypothesis relates to obvious relation

\footnotetext{
${ }^{8}$ Except for one session under PI with two independent groups due to no-show-ups of recruited participants.

${ }^{9}$ English translations of the experimental instructions are enclosed in Appendix B.

${ }^{10}$ Whenever possible, we base our hypotheses on the subgame perfect Nash equilibria which have the property that behavioral strategies at stage 1 (rule choice) are a strict Nash equilibrium given that play continues with the equilibrium investment strategies at stage 2 . In PI and NI this rules out the equilibria, where all players choose rule $L$. We refer to the standard justification for focussing on strict Nash equilibria, namely that non-strict equilibria are less robust since
} 
between distributional choices and individuals' degree of uncertainty concerning their own ability (i.e., the thickness of the veil):

\section{H1 (Information and redistribution)}

The size of the libertarian society is increasing in the degree of information of the players about their individual productivities. Conversely, the size of redistributive societies is decreasing in the degree of information.

As we have argued in Section 1, there is a large heterogeneity in the size of the welfare state across countries in the world. While the political economy literature explains this heterogeneity with differences in the countries' voting systems (Alesina and Glaeser, 2004), our model delivers the hypothesis that the observed heterogeneity is the result of an intermediate degree of uncertainty at the time when individuals vote by their feet. We summarize this finding in our second hypothesis:

\section{H2 (Coexistence of libertarianism and redistribution)}

Libertarian and redistributive societies only coexist under partial information. Under no information there only exists one society which redistributes according to the proportional rule, while under full information there is no redistribution at all. ${ }^{11}$

Starting with Tiebout's (1956) seminal contribution the literature on local public goods and fiscal competition has shown that voting by feet typically leads to a segregation of society, where individuals sort into different communities according to their personal characteristics. The pertinent literature is summarized in Epple and Nechyba (2004). Banzhaf and Walsh (2008) find strong evidence in favor of people voting with their feet with regard to environmental issues whereas Rhode and Strumpf (2003) argue that falling mobility costs would not lead to more Tiebout sorting but, on the contrary, to a weak increase in heterogeneity. Empirical evidence regarding the development of U.S. municipalities

there exist deviations which are not deterred by a lower payoff.

${ }^{11}$ Recall that under full information only the players with the lowest possible productivity may choose redistribution in equilibrium and hence there is no actual redistribution. 
between 1870 and 1990 does not allow them to refute their hypothesis. Since redistribution loses all its appeal in a segregated society, a fundamental question is, whether we obtain a similar result for our model. Given our theoretical analysis the answer is in the affirmative, which we state as our third and final hypothesis:

\section{H3 (Segregation of the society)}

A redistributive society is always segregated, that is, players with different productivities or different signals never choose the same redistribution rule.

\section{Results}

We report the results of our experiments in three steps. In a first subsection, we provide an overview of rule choices, the fraction of subjects actually participating in redistribution, and the investments under the three treatment conditions. Based on those findings, we analyze the pattern guiding individual decisions for or against redistribution in a second subsection. Finally, in the last subsection we compare individual choices with the stated preferences in the random-dictatorship questionnaire in order to show how strategic incentives influence the individual preference for redistribution. Notice that, for simplicity, we speak about signals in the following when referring to the signals players receive in PI and to the productivities players learn in FI prior to the rule choice.

\subsection{Aggregate Demand for Redistribution}

Our results on the distributional choices are largely in line with one basic theoretical prediction: subjects increase the level of redistribution for larger degrees of uncertainty. More specifically, there is a clear-cut convergence of subjects' choices under FI. Over all periods, in about $8 \%$ of the cases, subjects choose $E$, while $25 \%$ choose $P$. The vast majority, however, choose $L(67 \%)$. In contrast, there is less convergence under PI towards rule $L$. Over all periods, in $48 \%$ of all cases players choose $L, 36 \%$ choose $P$ and $16 \% E$. Finally, in $35 \%(49 \% / 16 \%)$ of cases in NI players choose $L(P / E$, respectively). Testing period-wise, the differences 
between treatments are predominantly significant across treatments. ${ }^{12}$ Figure 1 displays the development of rule choices over periods.

Comparing treatment conditions, there are significantly more $E$ choices in PI than in FI ( $p=0.03$, all following results rely on Wilcoxon Mann-Whitney Rank Sum Tests, two-sided, comparing mean rule choices per group and over periods), while only weakly significantly more $E$ choices in NI than in FI $(p=0.09)$, and no significant difference between PI and NI $(p=1)$. Likewise, there are significantly more $P$ choices in NI than in FI $(p=0.002)$, but no significant differences between PI and NI $(p=0.33)$, and between PI and FI $(p=0.25)$. Finally, there are significantly more $L$ choices in FI than in PI $(p=0.009)$, and between FI and NI $(p=0.002)$, but only weakly significantly differences between PI and NI $(p=0.08)$.

Controlling for signals we find a more detailed picture of rule choices under FI and PI, respectively. Table 1 summarizes the average choices depending on signals. The results, particularly for FI, show the expected positive relation between the signal and the preference for the $L$ rule. On the other hand, the majority of players receiving a signal of 1.2 in FI choose $P$. Likewise, $P$ is the most frequently chosen rule in NI, while surprisingly many players in this treatment condition also choose $L$. What is surprising, too, are the choices given the signal $m$ in PI. Players receiving this signal choose (roughly) equally likely $P$ and $L$ (i.e., redistribution and no redistribution), whereas players receiving the signal $\ell(h)$ choose predominantly $P(L)$.

Testing for treatment differences reveals no significant differences for the $E$ choices, $P$ choices, and $L$ choices between players with signals 1.2 in FI, players with the signal $\ell$ in PI and players in NI. ${ }^{13}$ On the other hand, players with signals 5 (3) in FI choose significantly more often $L$ and significantly less often $P$ and $E$ than players receiving signal $h(m)$ in PI ( 5 vs. $h: p=0.004 / p=0.004 / p=0.017$ and 3 vs. $m: p=0.004 / p=0.017 / p=0.004$, Wilcoxon Mann-Whitney Rank Sum Test, two-sided). Thus, players with low or unknown productivity seem to opt for similar redistribution regimes, whereas choices of highly productive and,

\footnotetext{
${ }^{12}$ Exceptions are periods 3, 5, 7, 14, 20, and 24, for all other periods $p<0.05$, Chi-squared test on count data, two-sided, correcting for the interdependencies within groups.

${ }^{13}$ There is only one exception that players under NI choose significantly more often $L$ than players with signal $\ell$ in PI ( $p=0.03$ ); for all differences $p>0.05$ (Wilcoxon Mann-Whitney Rank Sum Test, two-sided).
} 


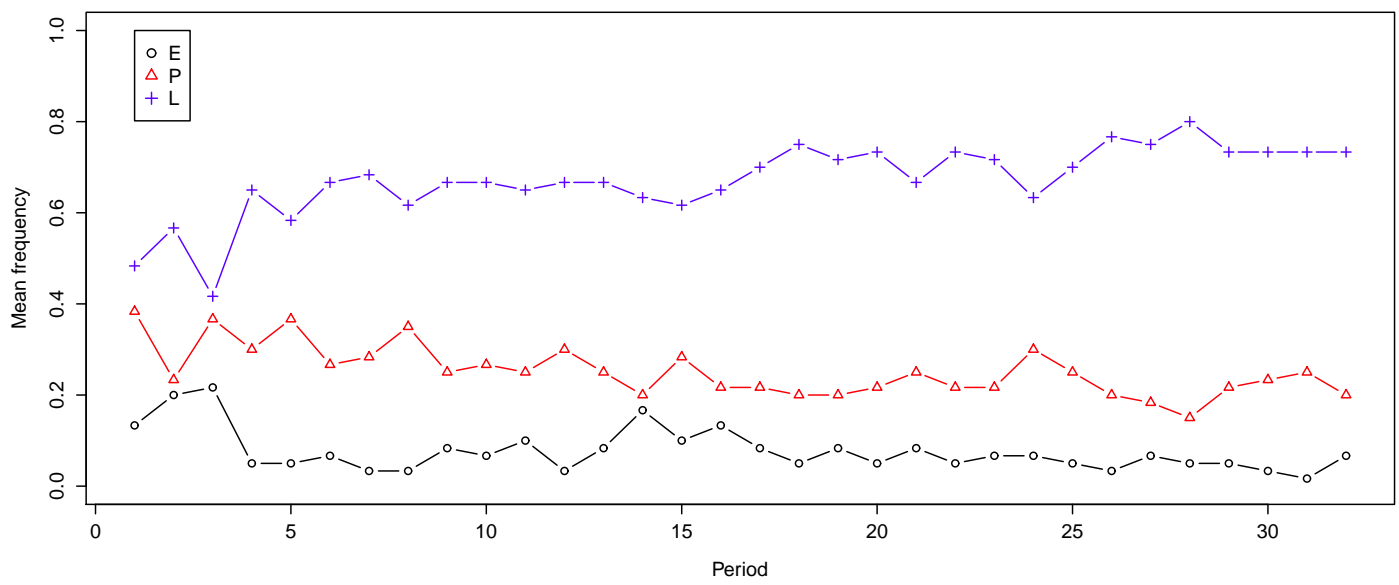

PI

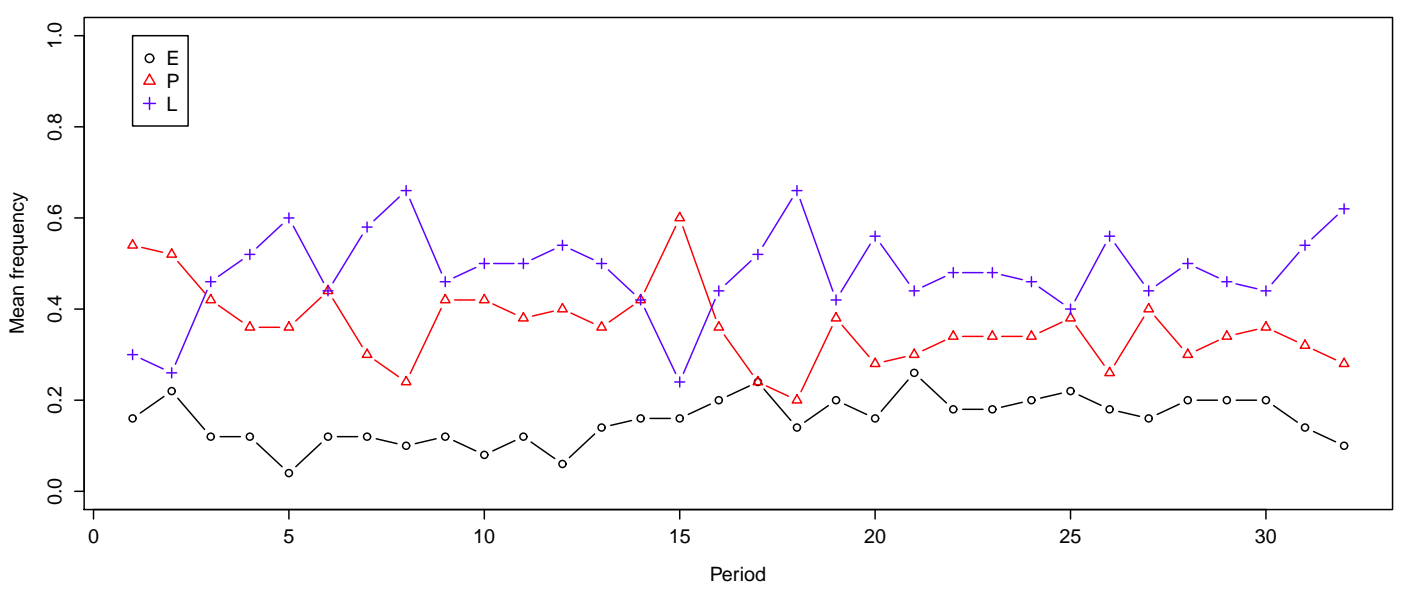

NI

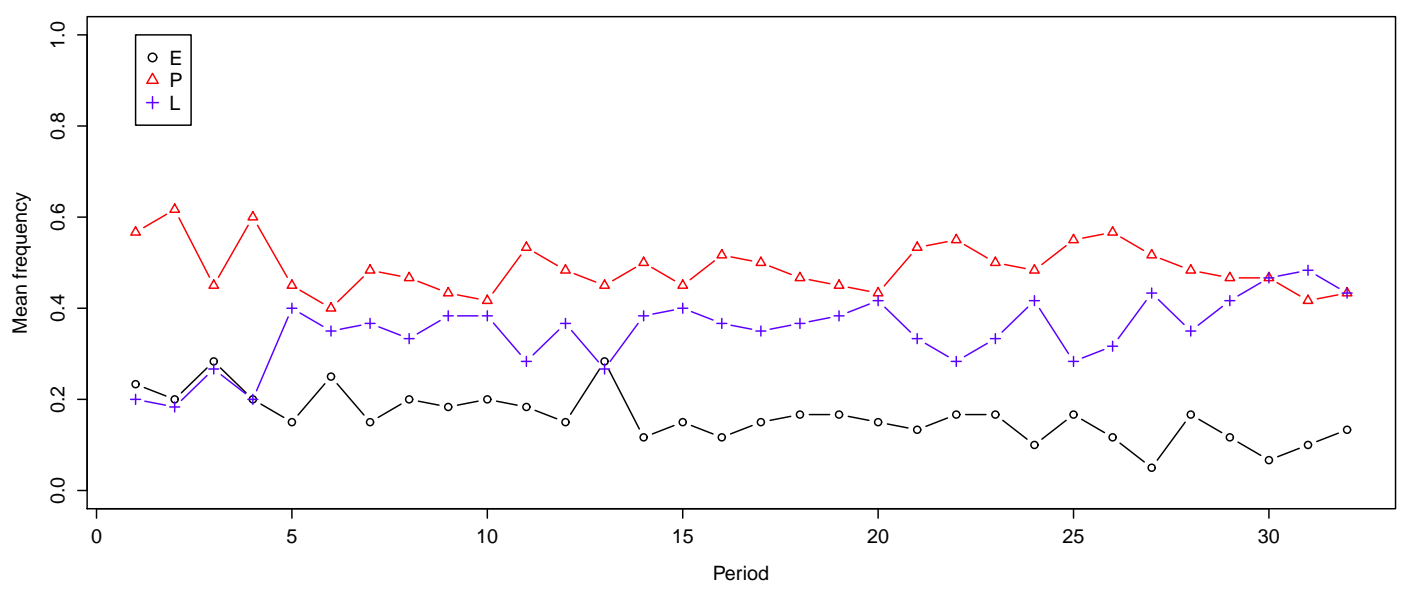

Figure 1: Development of rule choices over periods 


\begin{tabular}{|cc|cc|cc|cc|}
\hline \hline & & \multicolumn{2}{|c|}{$E$} & \multicolumn{2}{|c|}{$P$} & \multicolumn{2}{c|}{$L$} \\
\hline NI & all & .16 & $(.08)$ & .49 & $(.13)$ & .35 & $(.12)$ \\
\hline PI & all & .16 & $(.06)$ & .36 & $(.15)$ & .48 & $(.10)$ \\
& $\ell$ & .25 & $(.18)$ & .59 & $(.26)$ & .16 & $(.10)$ \\
& $m$ & .17 & $(.07)$ & .40 & $(.18)$ & .43 & $(.15)$ \\
& $h$ & .06 & $(.05)$ & .10 & $(.03)$ & .84 & $(.07)$ \\
\hline FI & all & .08 & $(.02)$ & .25 & $(.06)$ & .67 & $(.06)$ \\
& 1.2 & .19 & $(.05)$ & .59 & $(.11)$ & .22 & $(.09)$ \\
& 3 & .02 & $(.01)$ & .11 & $(.08)$ & .87 & $(.09)$ \\
& 5 & .01 & $(.01)$ & .02 & $(.02)$ & .97 & $(.02)$ \\
\hline \hline
\end{tabular}

Table 1: Average frequency of rule choices over treatments (between-group standard variation in parenthesis).

particularly, medium productive players differs with the degree of uncertainty. We will discuss this point in more detail in the next subsection.

One may argue that the observed deviations from the theoretical predictions are not the result of non-equilibrium behavior, but are rather driven by heterogeneity across groups, where every group is playing one Nash equilibrium (recall that there are multiple Nash equilibria in all treatments). That is, in contrast to our claim, it could be the case that groups coordinate perfectly on one Nash equilibrium, while the heterogeneity that we measure comes from differences across groups. However, comparing the mean variance of choices within groups with the variance of means across groups shows that the first number is for all treatments considerably larger than the second. Hence, we find heterogeneity within groups but not across groups: mean variance within groups of $P$ choices under FI $(\mathrm{PI} / \mathrm{NI})$ is $0.19(0.21 / 0.24)$ while the variance of mean choices of $P$ across groups under FI (PI/NI) is $0.004(0.02 / 0.02)$. Likewise, mean variance within groups of $E$ choices under FI (PI/NI) is $0.07(0.13 / 0.13)$, the variance of mean choices of $E$ across groups under FI (PI/NI) is $0.0004(0.003 / 0.007)$. Finally, mean variance within groups of $L$ choices under FI (PI/NI) is $0.22(0.24 / 0.22)$ while the variance of mean choices of $L$ across groups under FI (PI/NI) is $0.003(0.01 / 0.01)$.

Let us now have a look at the investments. Figure 2 box-plots the average investments within groups over treatments and rules. Despite its public good nature, we find positive investments under rule $E$. However, they are substantially 
less (6.01 in FI, 7.78 in PI, and 7.42 in NI) than under $P$ (8.56 in FI, 8.88 in PI, and 9.22 in NI) and under $L$ (9.93 in FI, 9.92 in PI, and 9.93 in NI). As a consequence, there are highly significant differences in the mean investment rates per group between rules $(p<0.001$ for FI, $p=0.008$ for PI, and $p<0.001$ for NI, Kruskal-Wallis tests, two-sided, comparing group averages across rules). On the other hand, there is only weak evidence suggesting that mean investment rates per group differ between treatment conditions keeping the rule constant ( $p=0.06$ for $E, p=0.10$ for $P$, and $p=0.85$ for $L$, Kruskal-Wallis tests, twosided, comparing group averages across FI, PI, and NI). Thus, in line with the theoretical prediction, the rule rather than the degree of uncertainty matters for the investment decision: players invest equally across treatment conditions, yet they invest more in $L$ than in $P$, and more in $P$ than in $E$.

This finding leads to the question whether investment under rule $E$ is low because players generally invest little under rule $E$ or whether $E$ specifically attracts low productivity players who - theoretically - do not invest if there is at least one other player under rule $E$. In other words, how important is the selection of productivities for the investment level of a rule. The answer is that selection is less important: except for two cases, we find no evidence that players with different productivities invest differently given a particular rule. ${ }^{14}$ Observe that this is in contrast to the theoretical prediction according to which players with different productivities invest differently under rule $E$ depending on the size of the subgroup under rule $E$. Our experimental data provides evidence that the rule selection itself rather than productivities matter for the investment decision: investments under redistribution, particularly under egalitarianism, are lower than under libertarianism.

Of course, the interesting question is how distributional choices and investment decisions translate into actual redistribution. For this purpose, one has to consider that subjects can end up without redistribution even if they choose $E$ or $P$ : the other players may invest nothing (e.g., this could be the case under rule $E$ ), or - even with investments - a group could consist of players with one

\footnotetext{
${ }^{14}$ The two exceptions are players choosing $E$ and $L$ in NI (where selecting the rule according to the productivity is impossible): here, high productive players invest significantly more $(8.42 / 10)$ than medium productive players $(8.26 / 9.95)$, and medium productive players invest significantly more than low productive players $(6.13 / 9.83 ; p=0.013 / p=0.04$, Kruskal-Wallis tests, twosided, comparing group averages).
} 


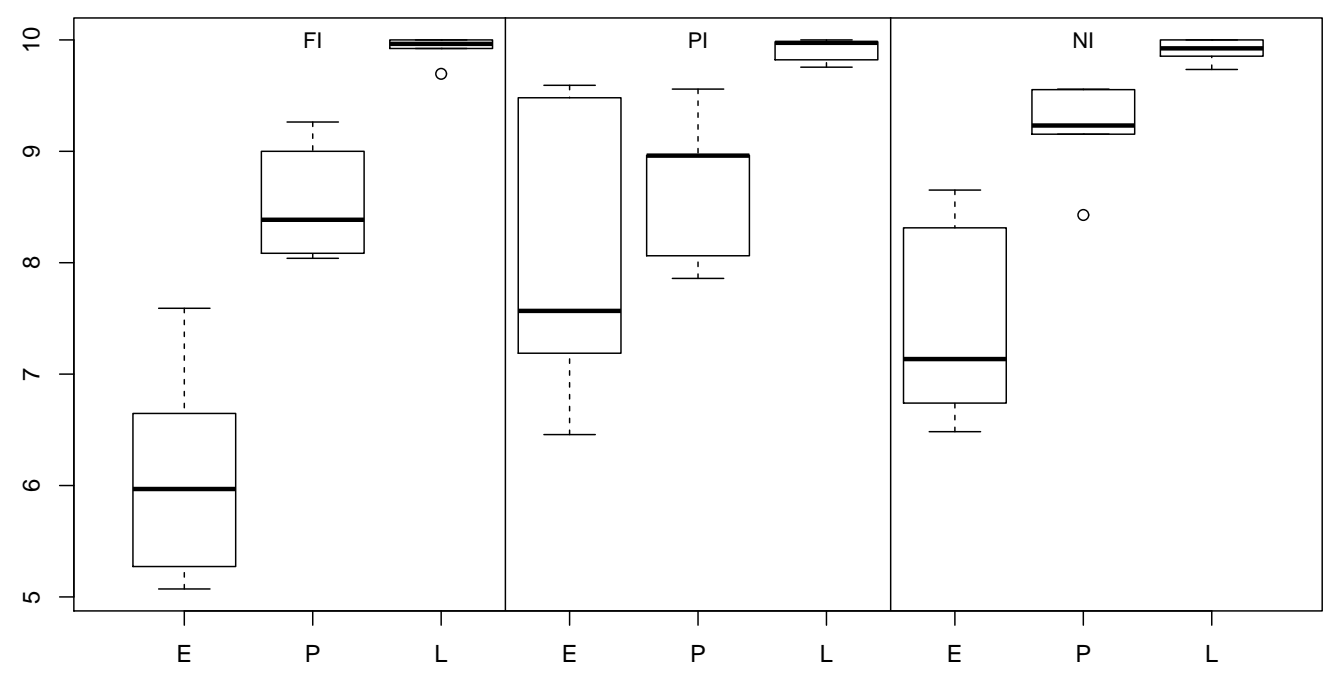

Figure 2: Average investment per group over treatments (the black bar is the median, black refers to the inner quartiles (block) and 1.5 of the inner quartiles (whisker)).

productivity class only (e.g., some low productivity players opt for rule $P$ while all other players choose $E$ or $L$ in FI). Excluding all cases in which players either opt for $L$, or choose $E$ or $P$ while there is no redistribution within the group under the same rule, Table 2 reports the mean frequency of players redistributing income under rule $E$ or $P$. The results show that there is very little redistribution in FI. ${ }^{15}$ On the other hand, following the results for distributional choice, there are surprisingly many (few) players redistributing income under $P$ in PI (NI), so that there is no significant difference between the two treatments $(p=0.19$, Wilcoxon Mann-Whitney Rank Sum Test, two-sided). Likewise, there is no significant difference between the number of players redistributing income under $E$ in PI and NI ( $p=0.93$, Wilcoxon Mann-Whitney Rank Sum Test, two-sided). Hence, despite the theoretical incentives, a substantial number of subjects redistribute income under rule $E$ in both treatments, while there is in total too much (too little) redistribution in PI (NI) relative to the theoretical prediction.

\footnotetext{
${ }^{15} p=0.018$, and $p=0.006$, Kruskal-Wallis tests, two-sided, comparing group averages for players redistributing income under $E$, and $P$, respectively, across FI, PI, and NI.
} 


\begin{tabular}{|cc|cc|cc|cc|}
\hline \hline & & \multicolumn{2}{|c|}{$E$} & \multicolumn{2}{|c|}{$P$} & \multicolumn{2}{c|}{ no redistribution } \\
\hline NI & all & .11 & $(.08)$ & .48 & $(.14)$ & .41 & $(.11)$ \\
\hline PI & all & .10 & $(.06)$ & .33 & $(.16)$ & .57 & $(.12)$ \\
& $\ell$ & .16 & $(.12)$ & .54 & $(.28)$ & .30 & $(.17)$ \\
& $m$ & .13 & $(.09)$ & .37 & $(.19)$ & .50 & $(.16)$ \\
& $h$ & .03 & $(.03)$ & .09 & $(.03)$ & .88 & $(.05)$ \\
\hline FI & all & .01 & $(.01)$ & .10 & $(.06)$ & .89 & $(.06)$ \\
& 1.2 & .01 & $(.02)$ & .17 & $(.12)$ & .82 & $(.12)$ \\
& 3 & .01 & $(.01)$ & .10 & $(.07)$ & .89 & $(.08)$ \\
& 5 & .01 & $(.01)$ & .02 & $(.02)$ & .97 & $(.02)$ \\
\hline \hline
\end{tabular}

Table 2: Average frequency of choices of actual redistribution ( $E$ and $P$ ) and no redistribution over treatments (between-group standard variation in parentheses).

Summarizing, there are three major findings from our analysis on redistributive choices:

1. There is more redistribution under NI and PI than under FI. However, there is no significant difference between the size of redistributive societies in PI and in NI. Compared with the game theoretic prediction, there is too much redistribution under PI (mainly driven by subjects with signal $m$ ) and too little redistribution under NI. Hence, hypothesis H1 is only partially confirmed by the experimental data.

2. In all treatments there is a coexistence of different distribution rules. Moreover, in NI and PI, but not in FI, there is a coexistence of libertarianism and actual redistribution. Hence, we must reject hypothesis H2.

3. There are non-segregated redistributive societies. In FI, and notably in PI, players with different productivities and signals, respectively, are in the same redistributive society. Hence, hypothesis H3 can be rejected.

\subsection{Individual Demand for Redistribution}

This subsection attempts to identify those factors that drive players into redistribution and that can explain the results in the previous sections concerning the aggregate demand for redistribution. For this purpose, we run a series of 
multinominal logit regressions, for each treatment condition separately. The dependent variable is the choice of either $L, P$, or $E$ in period $t$; the baseline in all regressions is $L$. That is, we search for factors that trigger the deviation from the libertarian regime and the migration to redistribution regimes.

Obviously, signals in FI and PI play an important rule for this decision. Therefore, we include in the regression for those two treatments the dummy variables signal $_{h}^{t}$ and signal ${ }_{m}^{t}$, where signal ${ }_{h}^{t}=1$ if a subject receives the signal $5(h)$ and signal $_{m}^{t}=1$ if a subject receives the signal $3(\mathrm{~m})$ in $t$. In other words, the baseline reveals the subjects' tendency to opt for redistribution once they receive a signal 1.2 or $\ell$, while signal $t_{h}^{t}$ and signal ${ }_{m}^{t}$ indicate the deviation from this tendency. Moreover, we include the variable period measuring potential time trends.

Next, we would like to analyze how the past performance of rules influences the rule choice. Therefore, we test for the influence of the information we provide while players choose their rule. We include the variables ave pays for $\Omega \in\{P, E\}$ in the regressions measuring the average payoff under rule $\Omega$ in period $t-1$. Here, one can argue that an increasing average payoff obtained under a rule increases its attraction. ${ }^{16}$ Likewise, we introduce the dummy variables $\omega_{\Omega}$ for $\Omega \in\{P, E\}$ which are one if the specific player chose rule $\Omega$ in period $t-1$, and are zero otherwise. Thus, the dummy variables test for path dependencies in the behavior of players (e.g., whether players who chose $E$ or $P$ in $t-1$ also do so in the following period).

Finally, we want to pay attention to the influence of the previous productivity on redistributional choice. For this purpose, we define the dummy variables $r_{h}^{t-1}$ and $r_{m}^{t-1}$, where $r_{h}^{t-1}=1\left(r_{m}^{t-1}=1\right)$ if a subject has a productivity of $5(3)$ in $t-1$ (notice that subjects know their $t-1$ productivities in $t$ ). These variables allow us to test for gambler's fallacy, i.e., for the players' failure to acknowledge the independence of productivity draws over periods (see, e.g., Croson and Sundali, 2005). On the other hand, the interplay with signal $l_{h}^{t}$ and signal $_{m}^{t}$ is of particular interest: For example, do players whose productivity is high in $t-1$ (i.e., $r_{h}^{t-1}=1$ ) and low in $t$ (i.e., signal ${ }_{h}^{t}=$ signal $_{m}^{t}=0$ ) opt differently for redistribution than players whose productivity is low in $t-1$ and $t$ ?

\footnotetext{
${ }^{16}$ One may argue that the number of players opting previously in favor of a certain rule influences the likelihood that the rule is chosen in the current period. As we do not find any systematic evidence for this claim, we do not include this variable into the following regressions.
} 
In all regressions, an absolute term is included. We apply individual error clusters. The number of observations (nobs) and the pseudo-r-squares $\left(R^{2}\right)$ are reported; the fitness of the models are tested on the basis of Wald-Chi ${ }^{2}$-tests. Asterisks indicate significance levels. ${ }^{17}$ We first discuss the results for NI (of course, we cannot test for the effect of signal $l_{h}^{t}$ and signal ${ }_{m}^{t}$ in this treatment condition). Estimations for mean marginal effects are reported in Table 3.

\begin{tabular}{|l|cc|cc|}
\hline \hline choice & \multicolumn{2}{|c|}{$E$} & \multicolumn{2}{c|}{$P$} \\
\hline period & $-.0017^{* *}$ & $(.0007)$ & $-.002^{*}$ & $(.0012)$ \\
ave pay & $.003^{* * *}$ & $(.0007)$ & -.0011 & $(.001)$ \\
ave pay $_{P}$ & $-.0043^{* * *}$ & $(.001)$ & $.0092^{* * *}$ & $(.002)$ \\
$\omega_{E}$ & $.2224^{* * *}$ & $(.059)$ & -.0199 & $(.058)$ \\
$\omega_{P}$ & $-.0533^{* *}$ & $(.001)$ & $.427^{* * *}$ & $(.0525)$ \\
$r_{h}^{t-1}$ & $.058^{* * *}$ & $(.059)$ & $.0886^{* *}$ & $(.0401)$ \\
$r_{m}^{t-1}$ & .0199 & $(.0269)$ & .0193 & $(.0393)$ \\
\hline nobs & \multicolumn{4}{|c}{60} \\
$R^{2}$ & \multicolumn{5}{|c}{$262.6^{* * *}$} \\
Wald-Chi $^{2}(14)$ & \multicolumn{5}{|c}{} \\
\hline \hline
\end{tabular}

Table 3: Mean marginal effect estimations (standard errors in parentheses) for NI; multinominal logit regression with rule choice as dependent variable and individual error clusters; baseline is the choice of $L$.

The results show a number of expected relations: as indicated by the sig-

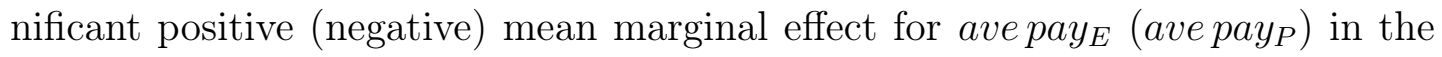
regression on $E$ choices, the success in terms of average payoffs of rule $E(P)$ increases (decreases) the probability to choose $E$ and not $L$, as well as the success of rule $P$ increases the probability to choose $P$ and not $L$ (see the significant positive mean marginal effect of ave pay $_{P}$ in the regression on $P$ ). Likewise, choosing $E(P)$ in the previous period increases (decreases) the probability to opt for $E$ in current period, whereas choosing $P$ in the previous period increases the probability to opt for $P$ in current period (see the significant mean marginal effects of $\omega_{E}$ and $\left.\omega_{P}\right)$. Consequently, the choice for redistribution rules seems to be "sticky," and depends on the success of the rule, while the overall probability to choose redistribution decreases over the course of the experiment (see the significant negative mean marginal effects of period).

\footnotetext{
$17 * * *$ indicates significance at a $p<0.01$ level, ${ }^{* *}$ at a $p<0.05$ level and ${ }^{*}$ at a $p<0.1$ level.
} 
What is surprising, though, is the significant positive mean marginal effect of $r_{h}^{t-1}$ in both regressions. It seems that players fall prey to an anticipated gambler's fallacy: whenever they were highly productive in the previous period, they opt for redistribution in the consecutive period. Similarly, if we change the reference case by including a variable $r_{\ell}^{t-1}$ (which is one if players had a productivity of 1.2 in $t-1$ and zero otherwise) for $r_{h}^{t-1}$, we find a significant negative mean marginal effect. ${ }^{18}$ That is, the previous productivity influences significantly the choice for or against redistribution in the current period. We will discuss the implications of those findings below. Before doing so, let us consider the results for the other treatments.

\begin{tabular}{|l|cc|cc|}
\hline \hline choice & \multicolumn{2}{|c|}{$E$} & \multicolumn{2}{c|}{$P$} \\
\hline period & -.0002 & $(.0014)$ & -.0021 & $(.0018)$ \\
signal $_{h}^{t}$ & $-.1747^{* * *}$ & $(.032)$ & $-.5236^{* * *}$ & $(.0433)$ \\
signal $_{m}^{t}$ & $-.1151^{* * *}$ & $(.0256)$ & $-.2301^{* * *}$ & $(.0473)$ \\
ave pay $_{E}$ & $.0031^{* * *}$ & $(.0008)$ & -.0015 & $(.0011)$ \\
ave pay $_{P}$ & $-.0021^{*}$ & $(.0011)$ & $.0053^{* * *}$ & $(.0012)$ \\
$\omega_{E}$ & $.1778^{* * *}$ & $(.0599)$ & .0292 & $(.0596)$ \\
$\omega_{P}$ & $-.0539^{*}$ & $(.0307)$ & $.3501^{* * *}$ & $(.0499)$ \\
$r_{h}^{t-1}$ & .0069 & $(.0313)$ & $.1566^{* * *}$ & $(.0427)$ \\
$r_{m}^{t-1}$ & .0285 & $(.0259)$ & $.0961^{* *}$ & $(.0382)$ \\
\hline nobs & \multicolumn{5}{|c|}{50} & \\
$R^{2}$ & \multicolumn{5}{|c|}{.264} \\
Wald-Chi $^{2}(18)$ & \multicolumn{5}{|c|}{$449.2^{* * *}$} \\
\hline \hline
\end{tabular}

Table 4: Mean marginal effect estimations (standard errors in parentheses) for PI; multinominal logit regression with rule choice as dependent variable and individual error clusters; baseline is the choice of $L$.

Table 4 reports the estimation results for PI. Consistent with our previous regression for NI, we find significant positive mean marginal effects of ave pay $y_{E}$ (ave pay $)$ and $\omega_{E}\left(\omega_{P}\right)$ on the probability to choose $E(P)$, and a weakly significant negative mean marginal effect of ave pay $y_{P}$ and $\omega_{P}$ on the probability to choose $E$. In contrast to the case for NI, the probability to choose redistribution does not significantly decrease over the course of the experiment (see the coefficients of period).

\footnotetext{
${ }^{18}$ Mean marginal effects are $-.0546{ }^{* * *}(.0176)$ for $E$ and $-.1004^{* *}(.0417)$ for $P$.
} 
In addition, we find the expected effects of signals: receiving a high or a medium signal decreases significantly the probability to opt both for $E$ and $P$ (see the significant mean marginal effects of signal $t_{h}^{t}$ and signal $_{m}^{t}$ ). Interestingly, the results reveal again the positive effect of $r_{h}^{t-1}$ on the probability to choose $P$. Furthermore, there is a similar effect (but smaller in size) for $r_{m}^{t-1}$, while we do not find this relation for the choice of $E$. That is, for the $P$ rule, high or medium productivity in the former period triggers the demand for redistribution in the following period, and severely confounds the effect of the current signal. ${ }^{19}$ Again, if we change the reference case by including a variable $r_{\ell}^{t-1}$ for $r_{h}^{t-1}$, we find a significant negative mean marginal effect for $P .{ }^{20}$ In other words, an important behavioral factor influencing the demand for redistribution is the relative change in productivities, both, as the interplay between past productivities and signals in PI, and based on beliefs in NI.

\begin{tabular}{|l|cc|cc|}
\hline \hline choice & \multicolumn{2}{|c|}{$E$} & \multicolumn{2}{c|}{$P$} \\
\hline period & $-.0013^{* * *}$ & $(.0004)$ & $-.0056^{* * *}$ & $(.0014)$ \\
signal $_{h}^{t}$ & $-.1093^{* * *}$ & $(.0176)$ & $-.4658^{* * *}$ & $(.0384)$ \\
signal $_{m}^{t}$ & $-.0665^{* * *}$ & $(.0178)$ & $-.3^{* * *}$ & $(.0502)$ \\
ave pay $_{E}$ & $.0007^{* *}$ & $(.0003)$ & .0017 & $(.0014)$ \\
ave pay $_{P}$ & $.0006^{* *}$ & $(.0003)$ & $.0053^{* * *}$ & $(.0014)$ \\
$\omega_{E}$ & $.2157^{* * *}$ & $(.0778)$ & $.457^{* * *}$ & $(.0815)$ \\
$\omega_{P}$ & $.0563^{* * *}$ & $(.0201)$ & $.5024^{* * *}$ & $(.0843)$ \\
$r_{h}^{t-1}$ & $.0442^{* *}$ & $(.0184)$ & $.3147^{* * *}$ & $(.0673)$ \\
$r_{m}^{t-1}$ & $.0367^{* *}$ & $(.0154)$ & $.2357^{* * *}$ & $(.0518)$ \\
\hline nobs & \multicolumn{5}{|c}{60} \\
$R^{2}$ & \multicolumn{5}{|c}{.465} \\
Wald-Chi $^{2}(18)$ & \multicolumn{5}{|c}{$487.7^{* * *}$} \\
\hline \hline
\end{tabular}

Table 5: Mean marginal effect estimations (standard errors in parentheses) for FI; multinominal logit regression with rule choice as dependent variable and individual error clusters; baseline is the choice of $L$.

To complete our analysis, let us consider now the FI condition. Table 5 reports the estimation results. Like for rule choices under NI, we find significant negative mean marginal effects of period, signal $l_{h}^{t}$, and signal $_{m}^{t}$ on the choice of $E$, and $P$,

\footnotetext{
${ }^{19}$ For instance, for a highly productive player in period $t-1$ who receives the signal $m$ in $t$, the sum of both marginal effects is almost zero (although a joint F-test rejects the hypothesis that the sum of both effects is zero at $p=0.028$ ).

${ }^{20}$ Mean marginal effects are $-.0134(.0308)$ for $E$ and $-.1457^{* * *}(.0376)$ for $P$.
} 
respectively. Also, $r_{h}^{t-1}$ and $r_{m}^{t-1}$ influence positively the choice for redistribution, in this treatment condition both for $E$ and $P$. Obviously, however, our results for FI differ from the other conditions, as ave pay $y_{E}$, ave pay $y_{P}, \omega_{P}$, and $\omega_{E}$ positively influence the choice for both types of redistribution (the first variable only for $E$ ). This result surprises, as it implies that players somewhat imprecisely differentiate between both types of redistribution. We interpret those results in light of our previous findings (cf. Table 2) that there is in fact very little actual redistribution in FI. Thus, it seems that players search rather unsystematically for any type of redistribution

Let us summarize our findings on the demand of redistribution:

1. There is evidence that along expected factors like the signal, the average payoff of a certain redistribution regime, and the previous choice in favor for redistribution, the previous productivity matters for the demand of redistribution.

2. In combination with the signal, the significant effect of the previous productivity leads to the finding that the expected relative change in productivities significantly influences the choice of redistribution: the larger the decrease in expected productivities, the larger the demand for redistribution.

We find the latter effect under both types of uncertainty, NI and PI. We even have evidence for this effect in the FI treatment, although there is no uncertainty involved, and virtually no redistribution taking place. This result provides important insights for the findings on the aggregate demand for redistribution summarized at the end of Section 4.2. Let us call a player optimistic (pessimistic) if the expected productivity conditional on the current signal is higher (lower) than the realized productivity in the previous period: ${ }^{21}$ as our regression results have shown, an optimistic player is less likely to opt for redistribution than a pessimistic player. Hence, different from the theoretical prediction, where players with the same signal always choose the same strategy, subjects in our experiment condition their behavior not only on the current signal, but also on the

\footnotetext{
${ }^{21}$ In NI there is no signal and hence the expected productivity conditional on the current signal is equal to the unconditional expected productivity. In FI the signal is given by the productivity in the current period and hence it is fully informative.
} 
realized productivity in the previous period. For NI this implies that we observe less redistribution than predicted because optimistic players (those with a low productivity in the previous period) are less inclined to choose redistribution compared to the theoretical benchmark. Moreover, in PI we observe more redistribution than predicted, in particular by subjects with signal $m$, because pessimistic players (those with a high productivity in the previous period) are more inclined to choose redistribution compared to the theoretical benchmark. Finally, the combined influence of the current signal and the previous productivity on the choice of redistribution also explains why there are non-segregated redistributive societies in FI and PI, a coexistence of libertarianism and actual redistribution in NI and $\mathrm{PI}$.

\subsection{Voting by Feet versus Dictatorship}

To conclude our result section, let us assess the influence of strategic considerations on the choice of rules in our experiment. For this purpose, we contrast the behavior in the actual experiment with the hypothetical statements at the end of the experiment on the subjects' preferred distribution rule given that they could dictate a rule for their entire group. That is, in NI they are asked to choose between $E, P$, and $L$, while in PI (FI) they have to choose a rule conditional on receiving a signal $\ell(1.2)$, a signal $m(3)$, and a signal $h(5){ }^{22}$ Table 6 shows the proportion of subjects who opted for the different rules in the different treatments conditional on their information concerning their productivity.

The comparison between dictatorship decisions and the mean individual choice for rules while playing reveals important differences: almost all subjects in all treatment conditions choose significantly less often $L$ in the dictatorship decision than in the actual play. This result is remarkable, given that subjects in PI and FI also choose conditional on their signals as dictators. Nonetheless, subjects with a high signal in PI and FI opt significantly less often for $L$ than on average in their actual play. This is also true for subjects with signal $m$ in PI; the only exception are subjects with productivity 3 in FI, for whom the dictatorship decision does not differ significantly from mean actual play in periods with a productivity of 3 ( $p=0.145$, for all other comparisons $p<0.05$, Wilcoxon Mann-Whitney

\footnotetext{
${ }^{22}$ A similar method has been applied by Konow (2003).
} 


\begin{tabular}{|cc|c|c|c|}
\hline \hline & & $E$ & $P$ & $L$ \\
\hline NI & all & .20 & .67 & .13 \\
\hline PI & all & .21 & .39 & .40 \\
& $\ell$ & .30 & .56 & .14 \\
& $m$ & .22 & .54 & .24 \\
& $h$ & .10 & .08 & .82 \\
\hline FI & all & .08 & .31 & .61 \\
& 1.2 & .23 & .60 & .17 \\
& 3 & .02 & .27 & .71 \\
& 5 & 0 & .05 & .95 \\
\hline \hline
\end{tabular}

Table 6: Average frequency of rule choices under dictatorship.

Rank Sum Test, two-sided). Along this line, subjects receiving no or low signals choose consistently across voting by feet and the dictatorship decision, whereas they do not once they receive medium or high signals. ${ }^{23}$ Figure 3 displays the mean results while playing ("v") and the dictatorship decision ("d") depending on the signal and treatment condition.

In sum, there is an important mismatch between the decisions of players while playing the game and the dictatorship decision particularly once they receive high or medium signals. On average, all players opt less often for $L$ in the dictatorship decision than in the actual play. Thus, it seems that strategic considerations in the actual play crowds out partly the intrinsic preference for redistribution. ${ }^{24}$

\footnotetext{
${ }^{23}$ Analyzing the correlation between mean choices under voting by feet and the dictatorship decision, in NI the correlation is 0.66 for $E, 0.6$ for $P$, and 0.64 for $L(p<0.01$ for the hypothesis of a zero correlation in all three cases, Pearson's product-moment correlation test, two-tailed). Likewise conditional on signal $\ell$ in PI (1.2 in FI), we find a correlation of 0.51 (0.34) for $E$, a correlation of $0.63(0.47)$ for $P$, and a correlation of $0.5(0.55)$ for $L$ (again, $p<0.01$ in in all cases, Pearson's product-moment correlation test, two-tailed). Conditional on signal $m$ in PI, the correlation is not significantly different from zero for $E$ (correlation 0.15 , $p=0.29), L$ (correlation $0.22, p=0.12$ ), but significantly different from zero for $P$ (correlation $0.38, p=0.006)$. Furthermore, conditional on signal $h$ in PI the correlation is not significantly different from zero for $E$ (correlation $-0.17, p=0.23$ ), $P$ (correlation $0.27, p=0.06$ ) and $L$ (correlation $-0.13, p=0.36$ ). Finally, conditional on productivity 3 (5) in FI the correlation is not significantly different from zero: It is -0.17 with $p=0.19(0.09$ with $p=0.47)$ for $E, 0.07$ with $p=0.6$ (0.13 with $p=0.33)$ for $P$, and 0.13 with $p=0.3(0.1$ with $p=0.44)$ for $L$.

${ }^{24}$ Of course, other factors like the missing optimism and pessimism resulting from changing productivities in the repeated play may also influence choices.
} 
FI
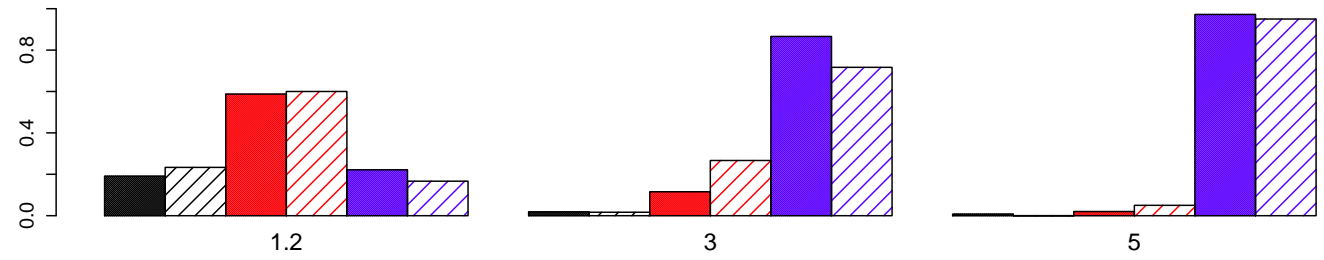

PI
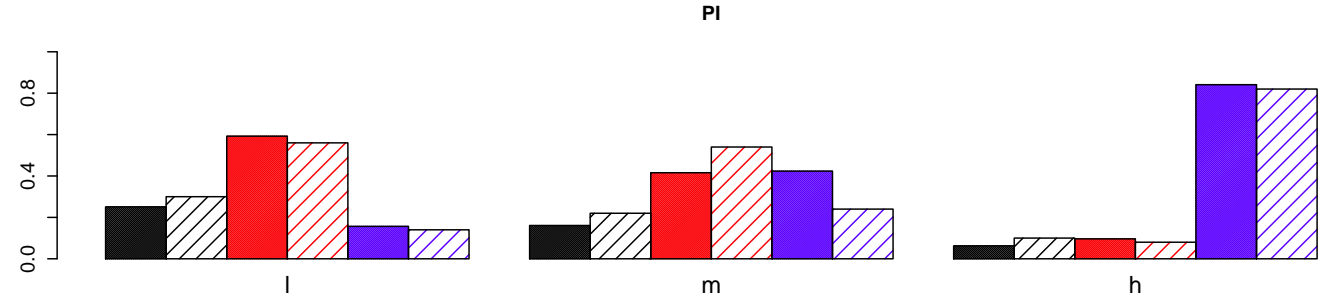

NI
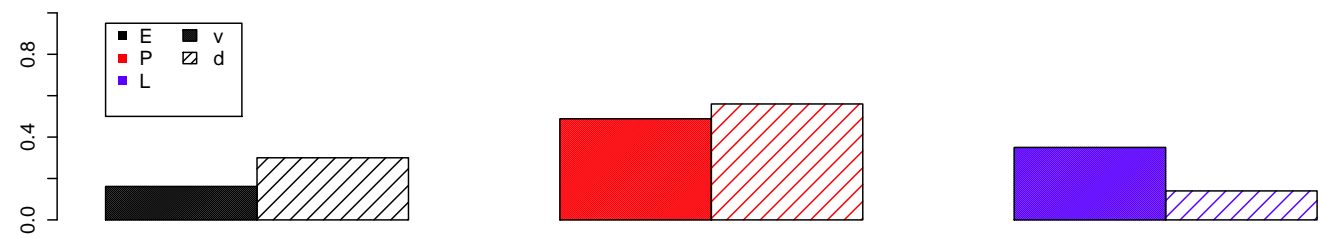

Figure 3: Mean rule choice while playing ("v") versus dictatorship decision on rule ("d") depending on the signal and treatment condition. 


\section{Conclusion}

In his famous book, John Rawls (1971) draws on a veil of ignorance to derive his principles of justice. At the center of our research is the idea that several persons decide simultaneously behind the veil of ignorance considering that others face the same decision. In other words, we analyze the strategic decision on redistribution behind a veil of ignorance which can be thick, thin or transparent. In our theoretical model as well as in our laboratory experiment individuals could choose between three distribution rules: a libertarian rule, where there is no redistribution; an egalitarian rule, where the proceeds from individual investments are shared equally; and a proportional rule, where the proceeds are shared in proportion to individual investments. Our theoretical results show that the level of redistribution increases with the degree of uncertainty, while redistributive societies are always segregated and they coexist with libertarian societies only under partial information, that is, under a thin veil of ignorance.

The experimental results only partly support these predictions. Under full information, there is a clear convergence to the libertarian rule. However, unlike the theoretical prediction, there is almost no difference in the level of redistribution under partial and no information. Thus, successful redistribution regimes may also be found in societies with limited uncertainty: relative to the theoretical prediction we find too much redistribution under partial information and too little redistribution under no information. Moroever, under both scenarios with imperfect information there is a coexistence of different redistribution rules, even despite significantly lower investments under the egalitarian rule.

Concerning the individual demand for redistribution, beyond obvious factors like the signal or past earnings under a rule we identified the expected relative change in productivities as another crucial factor: subjects in our experiment opt for redistribution whenever they expect their future productivity to be low relative to their past productivity, and they prefer a libertarian regime whenever they expect their future productivity to be relatively high. Thus, it is the subjects' sentiment rather than the expected absolute productivity which drives them in and out of redistribution. We find this effect under all degrees of uncertainty and for both redistribution rules. Consequently, both redistribution regimes coexist under all informational scenarios and societies are non-segregated, in general. 
In comparison to the stated preferences under a dictatorship regime, notably players of high and medium productivity under partial and full information opt less frequently for redistribution when voting strategically by feet. Hence, as predicted strategic considerations are indeed an important driving factor for the choice of distribution rules.

From our results we may conclude that welfare states are likely to emerge under various degrees of uncertainty, while there is generally more redistribution in societies where people believe in a large downward risk in terms of productivities, rather than in societies, where people believe in a large upward potential. This may explain why, for example, there is more redistribution in Europe than in the United States, where the belief to rise from rags to riches appears to be much stronger than in European countries. Moreover, the comparison with the dictatorship decisions suggests that larger welfare states can be sustained in less mobile societies, where voting by feet is limited, for example, due to restrictions in citizens' right to travel like in socialist countries. Although we have to be cautious when drawing far-ranging conclusions from a laboratory experiment, our results provide a new hypothesis for the observed heterogeneity in the size of welfare states across countries in the world. Whether this hypothesis is corroborated by empirical data or not is an open question for future research. 


\section{References}

[1] Alesina, A. and Fuchs-Schündeln, N. (2007). Good-bye Lenin (or not?): The Effect of communism on people's preferences. The American Economic Review, 97, 1507-1528.

[2] Alesina, A. and Glaeser, E.L. (2004). Fighting poverty in the US and Europe: A world of difference. Oxford: Oxford University Press.

[3] Andersson, F. and Lyttkens, C.H. (1999). Preferences for equity in health behind a veil of ignorance. Health Economics, 8, 369-378.

[4] Banzhaf, H.S. and Walsh, R.P. (2008). Do people vote with their feet? An empirical test of Tiebout's mechanism. American Economic Review, 98, 843863.

[5] Barberà S., Beviá, and C. \& Ponsatí, C. (2013). Meritocracy, egalitarianism and the stability of majoritarian organizations, mimeo, Universitat Autònoma de Barcelona.

[6] Beard, C. (1913). An economic interpretation of the constitution of the United States. Transaction Pub.

[7] Buchanan, J.M. and Tullock, G. (1962). The calculus of consent-logical foundations of constitutional democracy. Ann Arbor: University of Michigan Press.

[8] Cabrales, A., Nagel, R. and Rodríguez Mora, J. V. (2012). It is Hobbes, not Rousseau: an experiment on voting and redistribution. Experimental Economics, 15, 278-308.

[9] Cappelen, A., Drange Hole, A., Sörensen, E. and Tungodden, B. (2007). The pluralism of fairness ideals: an experimental approach. American Economic Review, 97, 818-827.

[10] Cappelen, A., Konow, J., Sørensen, E. and Tungodden, B. (2013). Just luck: An experimental study of risk taking and fairness. American Economic Review, 103, 1398-1413. 
[11] Carlsson, F., Gupta, G. and Johansson-Stenman, O. (2003). Choosing from behind a veil of ignorance in India. Applied Economics Letters, 10, 825-827.

[12] Cettolin, E. and Riedl, A. (2013). Justice under uncertainty. Discussions paper No. 036, University of Maastricht, Graduate School of Business and Economics.

[13] Corneo, G. and Grüner, H.P. (2002). Individual preferences for political redistribution. Journal of Public Economics, 83, 83-107.

[14] Durante, R. and Putterman, L. (2009). Preferences for redistribution and perception of fariness: an experimental study. Working Paper at SSRN.

[15] Epple, D. and Nechyba, T. (2004). Chapter 55: fiscal decentralization. In: Henderson, J.V. \& Thisse, J.-F. (eds.), Handbook of Regional and Urban Economics, Elsevier, vol 4, 2423-2480.

[16] Faravelli, M. (2007). How context matters: A survey based experiment on distributive justice. Journal of Public Economics, 91, 1399-1422.

[17] Fischbacher, U. (2007). z-Tree: Zurich toolbox for ready-made economic experiments. Experimental Economics, 10, 171-178.

[18] Frohlich, N., Oppenheimer, J. and Eavey, C. (1987). Laboratory results on Rawls' distributive justice. British Journal of Political Science, 17, 1-21.

[19] Frohlich, N. and Oppenheimer, J. (1990). Choosing justice in experimental democracies with production. American Political Science Review 84, 461477.

[20] Greiner, B. (2004). An online recruitment system for economic experiments. In: Kremer, K. \& Macho, V. (eds.), Forschung und wissenschaftliches Rechnen 2003, GWDG Bericht 63, Göttingen: Gesellschaft für Wissenschaftliche Datenverarbeitung, 79-93.

[21] Gürerk, Ö., Irlenbusch, B. and Rockenbach, B. (2006). The competitive advantage of sanctioning institutions. Science, 312, 108-111.

[22] Großer, J. and Reuben, E. (2013). Redistribution and market efficiency: an experimental study. Journal of Public Economics, 101, 39-52. 
[23] Harsanyi, J. (1953). Cardinal Utility in Welfare Economics and in the Theory of Risk-Taking. Journal of Political Economy 61, 434-435.

[24] Hayo, B. and Voigt, S. (2013). Endogenous constitutions: politics and politicians matter, economic outcomes don't. Journal of Economic Behavior $\&$ Organization, 88, 47-61.

[25] Johansson-Stenman, O., Carlsson, F. and Daruvala, D. (2002). Measuring future grandparents' preferences for equality and relative standing. The Economic Journal, 112, 362-383.

[26] Kauppinen, I. and Poutvaara, P. (2012). Preferences for redistribution among emigrants from a welfare state. Ifo Working Paper 120.

[27] Konow, J. (2000). Fair shares: Accountability and cognitive dissonance in allocation decisions. The American Economic Review, 90, 1072-1091.

[28] Konow, J. (2003). Which is the fairest one of all? A positive analysis of justice theories. Journal of Economic Literature, 41, 1188-1239.

[29] Konrad, K.A. and Morath, F. (2010). Social Mobility and Redistributive Taxation. Discussion Paper SP II 2010-15, Wissenschaftszentrum Berlin.

[30] Konrad, K.A. and Morath, F. (2011). Aspirations of the Middle Class: Voting on Redistribution and Status Concerns. Discussion Paper SP II 2011-102, Wissenschaftszentrum Berlin.

[31] Marx, K. (1933). Critique of the Gotha Programme. Lawrence \& Wishart: London.

[32] Meltzer, A. and Richard, S. (1981). A Rational Theory of the Size of Government. Journal of Political Economy 89, 914-927.

[33] Rawls, J. (1971). A Theory of Justice. Cambridge: Belknap.

[34] Rhode, P.W. and Strumpf, K.S. (2003). Assessing the importance of Tiebout sorting: local heterogeneity from 1850 to 1990. American Economic Review 93, 1648-1677. 
[35] Rockenbach, B. and Milinski, M. (2006). The efficient interaction of indirect reciprocity and costly punishment. Nature, 444, 718-723.

[36] Rutström, E. and Williams, M.B. (2000). Entitlements and fairness: an experimental study of distributive preferences. Journal of Economic Behavior $\&$ Organization, 43, 75-89.

[37] Samuelson, P.A. (1967). General proof that diversification pays. The Journal of Financial and Quantitative Analysis, 2, 1-13.

[38] Schokkaert, E. and Capeau, B. (1991). Interindividual differences in opinions about distributive justice. Kyklos, 44, 325-345.

[39] Schokkaert, E. and Overlaet, B. (1989). Moral intuitions and economic models of distributive justice. Social Choice and Welfare, 6, 19-31.

[40] Sen, A.K. (1966). Labour Allocation in a Cooperative Enterprise. The Review of Economic Studies, 33, 361-371.

[41] Tausch, F., Potters, J. and Riedl, A. (2013). Preferences for redistribution and pensions: What can we learn from experiments? Journal of Pension Economics and Finance, forthcoming.

[42] Ticchi, D. and Vindigni, A. (2010). Endogenous constitutions. The Economic Journal, 120, 1-39.

[43] Tiebout, C. (1956). A pure theory of local expenditures. Journal of Political Economy, 64, 416-424.

[44] Tyran, J.-R. and Sausgruber, R. (2006). A little fairness may induce a lot of redistribution in democracy. European Economic Review, 50, 469-485.

[45] Vickrey, W. (1945). Measuring Marginal Utility by Reactions to Risk. Econometrica, 13, 319-333.

[46] Yaari, M.E. and Bar-Hillel, M. (1984). On dividing justly. Social Choice and Welfare, 1, 1-24. 


\section{Appendix A}

Proof of Proposition 2.1: It remains to show that any Nash equilibrium $\sigma^{*}$ is payoff equivalent to $\sigma^{0}$, i.e., that every individual $i$ has a riskless equilibrium payoff $\pi_{i}\left(\sigma^{*} \mid r\right)=r w$ for all $r \in \mathcal{R}$.

Suppose by way of contradiction that there exists a Nash equilibrium $\sigma^{*}$ and an individual $i$ and $r \in \mathcal{R}$ such that $\pi_{i}\left(\sigma^{*} \mid r\right)>r w$ with positive probability. Let

$$
r^{*}=\max \left\{r \mid \exists j \text { with } \pi_{j}\left(\sigma^{*} \mid r\right)>r w \text { with positive probability }\right\}
$$

and let $i$ be an individual with $\pi_{i}\left(\sigma^{*} \mid r^{*}\right)>r^{*} w$ with positive probability. Then $\sigma_{i}^{*}\left(r^{*}\right) \neq L$ and there exists $r>r^{*}$ and $j \neq i$ with $\sigma_{j}^{*}(r)=\sigma_{i}^{*}\left(r^{*}\right)$. Let

$$
\bar{r}=\max \left\{r \mid \exists j \neq i \text { with } \sigma_{j}^{*}(r)=\sigma_{i}^{*}\left(r^{*}\right)\right\}
$$

Then $\bar{r}>r^{*}$ and there exists an individual $j$ with $\sigma_{j}^{*}(\bar{r})=\sigma_{i}^{*}\left(r^{*}\right)$. From (2) it follows that $\pi_{j}\left(\sigma^{*} \mid \bar{r}\right) \leq \bar{r} w$ with probability 1 . Moreover, (3), $\bar{r}>r^{*}$ and $\sigma_{j}^{*}(r)=\sigma_{i}^{*}\left(r^{*}\right)$ implies that $\pi_{j}\left(\sigma^{*} \mid \bar{r}\right)<\bar{r} w$ with positive probability. But then individual $j$ can increase her expected utility by deviating to $\sigma_{j}$ with $\sigma_{j}(\bar{r})=L$ and $\sigma_{j}(r)=\sigma_{j}^{*}(r)$ for all $r \neq \bar{r}$ contradicting the assumption that $\sigma^{*}$ is a Nash equilibrium.

Hence, if $\sigma^{*}$ is a Nash equilibrium then $\pi_{i}\left(\sigma^{*} \mid r\right) \leq r w$ for all $r \in \mathcal{R}$ and all individuals $i$. This together with the fact that every individual can guarantee herself the riskless payoff $r w$ by playing $\sigma_{i}^{0}$, implies that $\pi_{i}\left(\sigma^{*} \mid r\right)=r w$ for all $r \in \mathcal{R}$ and for all individuals $i$.

Proof of Proposition 2.2: Let $\sigma^{*}$ be a Nash equilibrium under full information and suppose there exists an individual $i$ and some $r>r^{1}$ with $\sigma_{i}^{*}(r)=E$. From Proposition 2.1 it follows that $\sigma_{j}^{*}\left(r^{\prime}\right) \neq E$ for all $j \neq i$ and $r^{\prime} \neq r$. Define

$$
t:=\left|\left\{i \mid \sigma_{i}^{*}(r)=E\right\}\right|
$$

If $t>r$, then with positive probability there is no investment under rule $E$ contradicting Proposition 2.1 according to which any $i$ with $\sigma_{i}^{*}(r)=E$ obtains 
the riskless payoff $r w$. Hence, $t \leq r$. If $t=n$, then any individual $j$ can improve over $\sigma_{j}^{*}$ by deviating to $\sigma_{j}$ with $\sigma_{j}\left(r^{1}\right)=E$ since there is always full investment under rule $E$. This contradicts the fact that $\sigma^{*}$ is a Nash equilibrium. Hence, $t<n$. Consider first the case where $t+1<r$. In this case there is always full investment under rule $E$ even if an additional individual chooses rule $E$. But then, any individual $j$ can improve over $\sigma_{j}^{*}$ by deviating to $\sigma_{j}$ with $\sigma_{j}\left(r^{1}\right)=E$ contradicting the fact that $\sigma^{*}$ is a Nash equilibrium.

Consider next the case where $t+1 \geq r$ and let $j$ deviate to $\sigma_{j}$ with $\sigma_{j}\left(r^{1}\right)=E$. Then the worst that can happen to $j$ is that there is no investment under rule $E$ if exactly $t+1$ players choose $E$. Let $p_{r}$ be the probability that an individual has productivity $r$. Then, for $r^{1}<2$,

$$
\begin{aligned}
& \mathbb{E}\left[\pi_{j}\left(\left(\sigma_{j}, \sigma_{-j}^{*}\right) \mid r^{1}\right)\right] \\
\geq & w\left[\left(1-p_{r}\right)^{t} r^{1}+\sum_{k=1}^{t-1}\left(\begin{array}{l}
t \\
k
\end{array}\right) p_{r}^{k}\left(1-p_{r}\right)^{t-k}\left(1+\frac{k}{k+1} r\right)+p_{r}^{t}\right]
\end{aligned}
$$

This implies that

$$
\mathbb{E}\left[\pi_{j}\left(\left(\sigma_{j}, \sigma_{-j}^{*}\right) \mid r^{1}\right)\right]>\mathbb{E}\left[\pi_{j}\left(\sigma^{*} \mid r^{1}\right)\right]=r^{1} w
$$

if

$$
1-\left(1-p_{r}\right)^{t}+p_{r}^{t}+r \sum_{k=1}^{t-1}\left(\begin{array}{l}
t \\
k
\end{array}\right) p_{r}^{k}\left(1-p_{r}\right)^{t-k} \frac{k}{k+1}>r^{1}\left(1-\left(1-p_{r}\right)^{t}\right)
$$

which is satisfied for $r^{1}$ sufficiently close to 1 . Hence, if $j$ is risk neutral or risk averse with a sufficiently weak risk aversion, then $j$ can improve over $\sigma_{j}^{*}$ contradicting the fact that $\sigma^{*}$ is a Nash equilibrium. This together with Proposition 2.1 implies that $\sigma_{i}^{*}(r)=L$ for all $i$ and for all $r>r^{1}$.

If all individuals with productivity larger than $r^{1}$ choose rule $L$, then any $i$ with productivity $r^{1}$ is indifferent between all rules as long as there is always full investment under the respective rules. For rule $E$ this is only true if at most $r^{1}$ individuals choose rule $E$. This proves the proposition. 
Proof of Lemma 2.1: Let $\mu=\mathbb{E}[r]$ be the expected productivity of an individual. Then the expected payoff of individual $i$ with $\sigma_{i} \in\{L, P\}$ is $\mu w$ independently of the number of individuals who have chosen rules $L$ or $P$. This proves the claim for the case of risk neutrality. If $i$ is risk averse and if $\sigma_{i}=P$, and if at least two individuals have chosen rule $P$, that is, $\left|S_{P}(\sigma)\right| \geq 2$, then from Samuelson (1967, Theorem I) it follows that

$$
\mathbb{E}\left[u_{i}\left(\pi_{i}(\sigma)\right)\right]>\mathbb{E}\left[u_{i}(r w)\right]
$$

Proof of Proposition 2.6: Let $\sigma^{*}$ be a Nash equilibrium and let $m=\left|S_{P}\left(\sigma^{*}\right)\right|$. If $m \geq 1$, then from Lemma 2.1 it follows that $\left|S_{L}\left(\sigma^{*}\right)\right|=0$. Hence, $\left|S_{E}\left(\sigma^{*}\right)\right|=$ $n-m$. We will show that $m=n$.

First observe that $n-m \leq\left\lfloor\frac{n+1}{2}\right\rfloor$ because otherwise $\left|S_{E}\left(\sigma^{*}\right)\right|>r^{M}$ and hence the expected utility of $i \in S_{E}\left(\sigma^{*}\right)$ is $\mathbb{E}\left[u_{i}\left(\pi_{i}\left(\sigma^{*}\right)\right)\right]=\mathbb{E}\left[u_{i}(w)\right]=u_{i}(w)$. But then $i$ could improve by deviating to $\sigma_{i}=L$ which yields an expected utility of $\mathbb{E}\left[u_{i}\left(r_{i} w\right)\right]>u_{i}(w)$.

Let $\sigma$ be an arbitrary strategy profile with $\left|S_{P}(\sigma)\right| \geq 2$ and suppose for the moment that $\left|S_{E}\left(\sigma^{*}\right)\right|=\left|S_{P}(\sigma)\right| \geq 2$. Then,

$$
\sum_{i \in S_{E}\left(\sigma^{*}\right)} \pi_{i}\left(\sigma^{*}\right) \leq \sum_{i \in S_{P}(\sigma)} \pi_{i}(\sigma)
$$

and " $<$ " with positive probability since by assumption $r^{1}<2 \leq\left|S_{E}\left(\sigma^{*}\right)\right|$. As $\pi_{i}(\sigma)=\pi_{j}(\sigma)=: \pi^{P}$ for all $i, j \in S_{P}(\sigma)$, from (4) it follows that

$$
\pi^{P} \geq \frac{1}{\left|S_{E}\left(\sigma^{*}\right)\right|} \sum_{i \in S_{E}\left(\sigma^{*}\right)} \pi_{i}\left(\sigma^{*}\right)
$$


and ">" with positive probability. Hence, for all $j \in S_{E}\left(\sigma^{*}\right)$,

$$
\begin{aligned}
\mathbb{E}\left[u_{j}\left(\pi^{P}\right)\right] & >\mathbb{E}\left[u_{j}\left(\frac{1}{\left|S_{E}\left(\sigma^{*}\right)\right|} \sum_{i \in S_{E}\left(\sigma^{*}\right)} \pi_{i}\left(\sigma^{*}\right)\right)\right] \\
& \geq \frac{1}{\left|S_{E}\left(\sigma^{*}\right)\right|} \sum_{i \in S_{E}\left(\sigma^{*}\right)} \mathbb{E}\left[u_{j}\left(\pi_{i}\left(\sigma^{*}\right)\right)\right] .
\end{aligned}
$$

This implies that there exists $j \in S_{E}\left(\sigma^{*}\right)$ with

$$
\mathbb{E}\left[u_{j}\left(\pi^{P}\right)\right]>\mathbb{E}\left[u_{j}\left(\pi_{j}\left(\sigma^{*}\right)\right)\right]
$$

Clearly, if $\left|S_{P}(\sigma)\right|>\left|S_{E}\left(\sigma^{*}\right)\right|$, then (5)-(7) continue to hold since, by Samuelson (1967, Theorem I), $\mathbb{E}\left[u_{j}\left(\pi^{P}\right)\right]$ is increasing in $\left|S_{P}(\sigma)\right|$. Hence, the expected utility of an individual under rule $P$ is strictly larger than under rule $E$, whenever there are at least as many individuals under rule $P$ as under rule $E$.

Suppose now by way of contradiction that $m<n$, that is, $\sigma_{i}^{*}=E$ for some $i$. The case $m=n-1$ is ruled out by Proposition 2.4. Hence, $m \leq n-2$. From $n-m \leq\left\lfloor\frac{n+1}{2}\right\rfloor$ it follows that $m \geq\left\lceil\frac{n-1}{2}\right\rceil$ and $m+1 \geq n-m$. Hence, if $i$ deviates to $\sigma_{i}=P$, then $\left|S_{P}\left(\sigma_{i}, \sigma_{-i}^{*}\right)\right| \geq\left|S_{E}\left(\sigma^{*}\right)\right| \geq 2$. As we have shown above, this implies that $i$ 's expected utility increases after the deviation to $\sigma_{i}=P$. But this contradicts our assumption that $\sigma^{*}$ is a Nash equilibrium. Hence, $m=n$ which proves that there exists no Nash equilibrium with $1 \leq\left|S_{P}\left(\sigma^{*}\right)\right|<n$.

Proof of Proposition 2.7: For necessity let $\sigma^{*}$ be a Nash equilibrium and suppose by way of contradiction that $\left|S_{E}\left(\sigma^{*}\right)\right| \geq 2$. Let $\sigma_{i}^{*}=E$. If $i$ 's risk aversion is sufficiently weak, then from (1) it follows that

$$
\mathbb{E}\left[u_{i}\left(\pi_{i}\left(\sigma^{*}\right)\right)\right]<\mathbb{E}\left[u_{i}(r w)\right]
$$

and hence $i$ could improve by deviating to rule $L$. This is a contradiction to the fact that $\sigma^{*}$ is a Nash equilibrium. Hence, $\left|S_{E}\left(\sigma^{*}\right)\right| \leq 1$. If $1 \leq\left|S_{P}\left(\sigma^{*}\right)\right| \leq n-1$, then either there exists $i$ with $\sigma_{i}^{*}=L$ or there exists a unique individual $i$ with $\sigma_{i}^{*}=E$. In both cases, by Lemma $2.1 i$ can improve by deviating to $\sigma_{i}=P$ which contradicts the assumption that $\sigma^{*}$ is a Nash equilibrium. Hence, either $\sigma_{i}^{*}=P$ 
for all $i$ or $\sigma_{i}^{*} \neq P$ for all $i$ and $\sigma_{j}^{*}=E$ for at most one $j$. Sufficiency is obvious given (1) and the fact that all individuals are assumed to have a sufficiently weak risk aversion.

Proof of Lemma 2.2: By $\pi_{i}(\sigma \mid s)$ we denote individual $i$ 's payoff given the strategy profile $\sigma$ conditional on signal $s \in\{\ell, m, h\}$. Let $\sigma^{*}$ be a Nash equilibrium and suppose by way of contradiction that $\sigma_{i}^{*}(h)=P$ for some $i$. Then, for $\sigma_{i}$ with $\sigma_{i}(h)=L$,

$$
\mathbb{E}\left[\pi_{i}\left(\sigma^{*} \mid h\right)\right] \leq \mathbb{E}\left[\pi_{i}\left(\left(\sigma_{i}, \sigma_{-i}^{*}\right) \mid h\right)\right]=\frac{1}{2}\left(r^{2}+r^{3}\right) w
$$

with " $<$ " if $\sigma_{j}^{*}(s)=P$ for some $j \neq i$ and some $s \in\{\ell, m\}$. Hence, if $i$ is risk neutral or risk averse and if the risk aversion is sufficiently weak, then $\sigma_{j}^{*}(s) \neq P$ for all $j \neq i$ and for all $s \in\{\ell, m\}$.

From $\sigma_{i}^{*}(h)=P$ it follows that $\sigma_{j}^{*}(\ell) \neq L$ for all $j \neq i$ because otherwise $j$ could improve by deviating to $P$ if the signal is $\ell$. From the first part of the proof it then follows that $\sigma_{j}^{*}(\ell)=E$ for all $j \neq i$ which implies that $\sigma_{j}^{*}(h) \neq E$ for all $j$ and hence, $\sigma_{j}^{*}(m) \neq E$ for all $j$. But then, any $j \neq i$ who is risk neutral or risk averse with a sufficiently weak risk aversion can improve by deviating to $\sigma_{j}$ with $\sigma_{j}(\ell)=P$ and $\sigma_{j}(s)=\sigma_{j}^{*}(s)$ for $s=m, h$, since

$$
\mathbb{E}\left[\pi_{j}\left(\sigma^{*} \mid \ell\right)\right] \leq \frac{1}{2}\left(r^{1}+r^{2}\right) w<\mathbb{E}\left[\pi_{j}\left(\left(\sigma_{j}, \sigma_{-j}^{*}\right) \mid \ell\right)\right]
$$

because there is always full investment under $P$ and $\sigma_{i}^{*}(h)=P$. This contradiction proves that $\sigma_{i}^{*}(h) \neq P$ for all $i$.

Suppose now that $\sigma_{i}^{*}(m)=P$ for some $i$. Then under risk neutrality or sufficiently weak risk aversion, $\sigma_{j}^{*}(\ell) \neq P$ for all $j \neq i$ and similar to the argument above we conclude that $\sigma_{j}^{*}(\ell) \neq L$ for all $j \neq i$ and hence, $\sigma_{j}^{*}(\ell)=E$ for all $j \neq i$. This implies $\sigma_{j}^{*}(h) \neq E$ and $\sigma_{j}^{*}(m) \neq E$ for all $j$. But then any $j \neq i$ with $\sigma_{j}^{*}(\ell)=E$ can improve by deviating to $\sigma_{j}$ with $\sigma_{j}(\ell)=P$ and $\sigma_{j}(s)=\sigma_{j}^{*}(s)$ for $s=m, h$ (cf. the argument above). This contradiction proves that $\sigma_{i}^{*}(m) \neq P$ for all $i$. 
Proof of Proposition 2.8: Let $r^{3}>2$ and let $\sigma^{*}$ be a Nash equilibrium under partial information. From Lemma 2.2 it follows that $\sigma_{i}^{*}(h) \neq P$ and $\sigma_{i}^{*}(m) \neq P$ for all $i$. Suppose by way of contradiction that there exists an individual $i$ with $\sigma_{i}^{*}(h)=E$. Then, if $i$ 's risk aversion is sufficiently weak, it follows that $\sigma_{j}^{*}(s) \neq E$ for all $j \neq i$ and $s=\ell, m$. Define

$$
t:=\left|\left\{i \mid \sigma_{i}^{*}(h)=E\right\}\right|
$$

Suppose by way of contradiction that $t>r^{2}$. Then with positive probability some player $i$ with $\sigma_{i}^{*}(h)=E$ does not invest and hence, every player $i$ with $\sigma_{i}^{*}(h)=E$ can improve by deviating to rule $L$ given $s=h$, if $i$ 's risk aversion is sufficiently weak. This contradiction proves that $t \leq r^{2}$.

Consider first the case where $t=n$. Let $j$ be an arbitrary individual. Then $\sigma_{j}^{*}(\ell) \in\{L, P\}$ and hence

$$
\mathbb{E}\left[\pi_{j}\left(\sigma^{*} \mid \ell\right)\right]=\frac{w}{2}\left(r^{1}+r^{2}\right) .
$$

If $j$ deviates to $\sigma_{j}$ with $\sigma_{j}(\ell)=E$, then

$$
\begin{aligned}
\mathbb{E} & \left.\pi_{j}\left(\left(\sigma_{j}, \sigma_{-j}^{*}\right) \mid \ell\right)\right]=\frac{1}{2} \mathbb{E}\left[\pi_{j}\left(\left(\sigma_{j}, \sigma_{-j}^{*}\right) \mid \ell\right) \mid r^{1}\right]+\frac{1}{2} \mathbb{E}\left[\pi_{j}\left(\left(\sigma_{j}, \sigma_{-j}^{*}\right) \mid \ell\right) \mid r^{2}\right] \\
=\frac{w}{2} & {\left[\left(\frac{2}{3}\right)^{n-1} r^{1}+\sum_{k=1}^{n-1}\left(\begin{array}{c}
n-1 \\
k
\end{array}\right)\left(\frac{1}{3}\right)^{k}\left(\frac{2}{3}\right)^{n-1-k}\left(1+\frac{k}{k+1} \frac{r^{2}+r^{3}}{2}\right)\right.} \\
+ & \left.\sum_{k=0}^{n-1}\left(\begin{array}{c}
n-1 \\
k
\end{array}\right)\left(\frac{1}{3}\right)^{k}\left(\frac{2}{3}\right)^{n-1-k} \frac{1}{k+1}\left(\frac{k}{2}\left(r^{2}+r^{3}\right)+r^{2}\right)\right] \\
>\frac{w}{2} & {\left[\left(\frac{2}{3}\right)^{n-1} r^{1}+\sum_{k=1}^{n-1}\left(\begin{array}{c}
n-1 \\
k
\end{array}\right)\left(\frac{1}{3}\right)^{k}\left(\frac{2}{3}\right)^{n-1-k}\left(1+\frac{k}{k+1} r^{2}\right)\right.} \\
+ & \left.\sum_{k=0}^{n-1}\left(\begin{array}{c}
n-1 \\
k
\end{array}\right)\left(\frac{1}{3}\right)^{k}\left(\frac{2}{3}\right)^{n-1-k} r^{2}\right] \\
=\frac{w}{2} & {\left[\left(\frac{2}{3}\right)^{n-1} r^{1}+\sum_{k=1}^{n-1}\left(\begin{array}{c}
n-1 \\
k
\end{array}\right)^{k}\left(\frac{1}{3}\right)^{k}\left(\frac{2}{3}\right)^{n-1-k}\left(1+\frac{k}{k+1} r^{2}\right)+r^{2}\right] }
\end{aligned}
$$


where the inequality follows from the fact that $r^{3}>r^{2}$. Hence,

$$
\mathbb{E}\left[\pi_{j}\left(\left(\sigma_{j}, \sigma_{-j}^{*}\right) \mid \ell\right)\right]>\frac{w}{2}\left(r^{1}+r^{2}\right)
$$

if

$$
1-\left(\frac{2}{3}\right)^{n-1}+\sum_{k=1}^{n-1}\left(\begin{array}{c}
n-1 \\
k
\end{array}\right)\left(\frac{1}{3}\right)^{k}\left(\frac{2}{3}\right)^{n-1-k} \frac{k}{k+1}>r^{1}\left(1-\left(\frac{2}{3}\right)^{n-1}\right)
$$

which is satisfied for $r^{1}$ sufficiently close to 1 . Hence, if $j$ 's risk aversion is sufficiently weak, then $j$ can improve by deviating to $\sigma_{j}$ which contradicts our assumption that $\sigma^{*}$ is a Nash equilibrium.

Consider now the case where $2 \leq t<n$. As above let $j$ be an arbitrary individual with $\sigma_{j}^{*}(\ell) \in\{L, P\}$. If $j$ deviates to $\sigma_{j}$ with $\sigma_{j}(\ell)=E$, then the worst that can happen is that individuals with productivity $r^{2}$ do not invest under rule $E$ if $t+1$ individuals have chosen rule $E$. Hence,

$$
\begin{aligned}
& \mathbb{E}[\left.\pi_{j}\left(\left(\sigma_{j}, \sigma_{-j}^{*}\right) \mid \ell\right)\right]=\frac{1}{2} \mathbb{E}\left[\pi_{j}\left(\left(\sigma_{j}, \sigma_{-j}^{*}\right) \mid \ell\right) \mid r^{1}\right]+\frac{1}{2} \mathbb{E}\left[\pi_{j}\left(\left(\sigma_{j}, \sigma_{-j}^{*}\right) \mid \ell\right) \mid r^{2}\right] \\
& \geq \frac{w}{2} {\left[\left(\frac{2}{3}\right)^{t} r^{1}+\sum_{k=1}^{t-1}\left(\begin{array}{c}
t \\
k
\end{array}\right)\left(\frac{1}{3}\right)^{k}\left(\frac{2}{3}\right)^{t-k}\left(1+\frac{k}{k+1} \frac{r^{2}+r^{3}}{2}\right)\right.} \\
&+\left.\left(\frac{1}{3}\right)^{t}+\sum_{k=0}^{t-1}\left(\begin{array}{c}
n-1 \\
k
\end{array}\right)\left(\frac{1}{3}\right)^{k}\left(\frac{2}{3}\right)^{t-k} \frac{1}{k+1}\left(\frac{k}{2}\left(r^{2}+r^{3}\right)+r^{2}\right)+\left(\frac{1}{3}\right)^{t}\right] \\
&>\frac{w}{2} {\left[\left(\frac{2}{3}\right)^{t} r^{1}+\sum_{k=1}^{t-1}\left(\begin{array}{c}
t \\
k
\end{array}\right)\left(\frac{1}{3}\right)^{k}\left(\frac{2}{3}\right)^{t-k}\left(1+\frac{k}{k+1} r^{2}\right)\right.} \\
&\left.+2\left(\frac{1}{3}\right)^{t}+\sum_{k=0}^{t-1}\left(\begin{array}{c}
t \\
k
\end{array}\right)\left(\frac{1}{3}\right)^{k}\left(\frac{2}{3}\right)^{t-k} r^{2}\right]
\end{aligned}
$$

where the inequality follows from the fact that $r^{3}>r^{2}$. Hence,

$$
\mathbb{E}\left[\pi_{j}\left(\left(\sigma_{j}, \sigma_{-j}^{*}\right) \mid \ell\right)\right]>\frac{w}{2}\left(r^{1}+r^{2}\right)
$$




$$
1-\left(\frac{2}{3}\right)^{t}+\left(\frac{1}{3}\right)^{t}+r^{2}\left[\sum_{k=1}^{t-1}\left(\begin{array}{l}
t \\
k
\end{array}\right)\left(\frac{1}{3}\right)^{k}\left(\frac{2}{3}\right)^{t-k} \frac{k}{k+1}-\left(\frac{1}{3}\right)^{t}\right]>r^{1}\left(1-\left(\frac{2}{3}\right)^{t}\right)
$$

which is easily seen to be satisfied for $r^{1}$ sufficiently small to 1 . Hence, if $j$ 's risk aversion is sufficiently weak, then $j$ can improve by deviating to $\sigma_{j}$ which contradicts our assumption that $\sigma^{*}$ is a Nash equilibrium.

Finally, consider the case where $t=1$, that is, there is a unique player $i$ with $\sigma_{i}^{*}(h)=E$. Observe that this implies that $r^{2} \leq 2$ because otherwise every $j \neq i$ could improve by deviating to rule $P$ if the signal is $h$. As above let $j$ be an arbitrary individual with $\sigma_{j}^{*}(\ell) \in\{L, P\}$. If $j$ deviates to $\sigma_{j}$ with $\sigma_{j}(\ell)=E$, then the worst that can happen is that $i$ does not invest under rule $E$ if $i$ 's productivity is $r^{2}$ and there are two individuals under rule $E$. However, $i$ invests his full endowment if the productivity is $r^{3}$ since $r^{3}>2$ by assumption. Hence,

$$
\begin{aligned}
& \mathbb{E}\left[\pi_{j}\left(\left(\sigma_{j}, \sigma_{-j}^{*}\right) \mid \ell\right)\right]=\frac{1}{2} \mathbb{E}\left[\pi_{j}\left(\left(\sigma_{j}, \sigma_{-j}^{*}\right) \mid \ell\right) \mid r^{1}\right]+\frac{1}{2} \mathbb{E}\left[\pi_{j}\left(\left(\sigma_{j}, \sigma_{-j}^{*}\right) \mid \ell\right) \mid r^{2}\right] \\
\geq & \frac{w}{2}\left[\frac{2}{3} r^{1}+\frac{1}{3}\left(1+\frac{1}{4} r^{3}\right)+\frac{2}{3} r^{2}+\frac{1}{3}\left(1+\frac{1}{4} r^{3}\right)\right] \\
= & \frac{w}{3}\left[1+r^{1}+r^{2}+\frac{1}{4} r^{3}\right]>\frac{w}{2}\left(r^{1}+r^{2}\right)
\end{aligned}
$$

which is easily seen to be satisfied for $r^{1}$ sufficiently small to 1 since $r^{2} \leq 2<r^{3}$. Hence, if $j$ 's risk aversion is sufficiently weak, then $j$ can improve by deviating to $\sigma_{j}$ which contradicts our assumption that $\sigma^{*}$ is a Nash equilibrium.

We therefore conclude that $\sigma_{i}^{*}(h)=L$ for all $i$. Since $r^{1}<2$ it follows that $\sigma_{i}^{*}(m)=E$ for at most one $i$. Otherwise, if at least two individuals choose rule $E$ given signal $m$, then every $i$ with $\sigma_{i}^{*}(m)=E$ could improve by deviating to $\sigma_{i}$ with $\sigma_{i}(m)=L$ if $i$ 's risk aversion is sufficiently weak, since there is a positive probability that not all individuals invest their full endowment under rule $E$. However, if $\sigma_{i}^{*}(m)=E$ for some $i$, then $\sigma_{j}^{*}(\ell) \neq E$ for all $j \neq i$ and every individual $j \neq i$ could improve by deviating to $\sigma_{j}$ with $\sigma_{j}(\ell)=E$ which follows from the same argument used above for the case $t=1$. This contradiction proves 
that $\sigma_{i}^{*}(m)=L$ for all $i$.

It remains to prove that either $\sigma_{i}^{*}(\ell)=P$ or $\sigma_{i}^{*}(\ell) \neq P$ for all $i$ and $\sigma_{j}^{*}(\ell)=E$ for at most one $j$. If all individuals' risk aversion is sufficiently weak, there exists no Nash equilibrium $\sigma^{*}$ with $1 \leq\left|\left\{i \mid \sigma_{i}^{*}(\ell)=P\right\}\right| \leq n-1$, which follows from a similar argument as in the proof of Proposition 2.7. Hence, it remains to consider the case where either $\sigma_{i}^{*}(\ell)=P$ for all $i$ or $\sigma_{i}^{*}(\ell) \neq P$ for all $i$. The first is obviously a Nash equilibrium. If $\sigma_{i}^{*}(\ell) \neq P$ for all $i$, then $\sigma^{*}$ is a Nash equilibrium if and only if $\sigma_{i}^{*}(\ell)=E$ for at most one $i$. Otherwise, if $\sigma_{i}^{*}(\ell)=E$ for more than one $i$, with positive probability some individual does not invest under rule $E$ and hence, every $i$ with $\sigma_{i}^{*}(\ell)=E$ can improve by deviating to rule $L$ whenever $i$ 's risk aversion is sufficiently weak. This proves the proposition.

\section{Appendix B: Instructions for the PI treatment}

\section{General explanations for participants ${ }^{25}$}

You are taking part in an economic experiment. You can earn a significant sum of money, depending on your decisions and the decisions of other participants. It is therefore very important that you pay attention to the following points.

The instructions you have received from us are intended solely for your private information. During the experiment, you will not be allowed to communicate with anyone. Should you have any questions, please direct them directly to us. Not abiding by this rule will lead to exclusion from the experiment and from any payments.

In this experiment, we calculate in Taler, rather than in Euro. Your entire income will therefore initially be calculated in Taler. The Taler will later be exchanged into Euros as 1 Taler $=0.30$ Euros. You will be paid in cash at the end of the experiment. For your participation in this experiment, you receive an initial income of 5 Euros. We will arrange the cashing out in a way that only the

\footnotetext{
${ }^{25}$ Translations of the German originals (which are available from the authors upon request). Differences for the other treatment conditions are indicated by footnotes.
} 
experimenter and you get to know your earnings. The following pages outline the exact procedure of the experiment.

\section{Exact procedure of the experiment}

General information At the beginning of the experiment you will be randomly assigned to a group of ten players. During the experiment, you only interact with members of your group. If we talk about persons in the instructions we refer only to members of your group.

The experiment consists of 32 rounds. At the beginning of each round, you have to choose a rule. There are three alternative rules, $A, B$, and $C$. In each round you receive an initial endowment of 10 Taler. Then you have to decide upon the amount of Taler out of the endowment you want to invest into a project. You keep the rest of your endowment for yourself. Your income in each round consists of two parts, your income of the project and the Taler you did not invest into the project. The rule determines your income from the project. The difference between the rules is explained below.

Investments The Taler you invest into the project increase the profit of the project. For this purpose, we multiply the Taler invested with an individual factor. This factor can be $1.2,3$, or 5 . At the beginning of a every round you receive a new factor. Each of the three factors is equally likely, and will be randomly determined for each member of the group independent from the factors of other group members.

Example: You invest 2 Taler into the project. Your individual factor is 1.2. The profit of the project is 2.4 Taler.

After you have made your investment into the project and the profit of the project has been calculated as your investment times your factor, the rule that you have chosen before determines your income from the project.

Rules At the beginning of each round every person chooses either rule $A, B$ or $C$ : 
- Under rule $A$ we sum up the projects' profits of all persons who have chosen $A$, and divide the sum equally among the persons who have chosen $A$. Therefore, your income from the project is the sum of the projects' profits of all persons who have opted for rule $A$, divided by the number of persons who have opted for rule $A$ (independent of the individual profits of the projects).

Example: You and another person choose rule $A$. You invest 2 Taler, your individual factor is 1.2. The other person invests 1 Taler, and has an individual factor of 5 . The profit from your project is 2.4 Taler, the profit from the other person's project is 5 Taler. Your income from the project is $(2.4+5) / 2=3.7$ Taler.

- Under rule $B$ we sum up the projects' profits of all persons who have chosen $B$, and divide the sum proportionally among the persons who have chosen $B$. Your proportion equals the share of your investment in the sum of investments undertaken by all persons who have chosen rule $B$. Therefore, your income of the project is the sum of the projects' profits of all persons who have opted for rule $B$, multiplied by your investment into the project, and divided by the sum of investments of all persons who have opted for rule $B$.

Example: You and another person choose rule B. You invest 2 Taler, your individual factor is 1.2. The other person invests 1 Taler, and has an individual factor of 5. The profit of your project is 2.4 Taler, the profit of the other person's project is 5 Taler. Your income of the project is $(2.4+5) * 2 /(2+1)=4.9$ Taler.

- Under rule $C$ your income of the project equals your project's profit.

Example: You and another person choose rule $C$. You invest 2 Taler, your individual factor is 1.2. The other person invests 1 Taler, and has an individual factor of 5 . The profit of your project is 2.4 Taler, the profit of the other person's project is 5 Taler. Your income of the project is 2.4 Taler. 
Exact procedure for the course of a round At the beginning of each round you have to choose a rule. Please consider that you have to choose a rule before you know your exact individual factor. This means that we tell you two factors prior to your choice of a rule. Your individual factor equals one of the two factors with same probability, but you do not know which one. Only after you have chosen the rule, you will receive precise information about your individual factor. In addition, we inform you about the factors of all other persons opting for the same rule you have chosen. ${ }^{26}$ Then you have to determine your investment into the project. Finally, we inform you about your income from the project. Your income of the round consists of your income of the project plus the rest of the endowment you did not invest into the project.

Example: You choose rule $C$. You invest 2 Taler, your individual factor is 1.2. The profit of you project is 2.4 Taler. You income of the round is $2.4+8=10.8$ Taler.

At the end of each round you will receive a detailed overview of the rule choices, the investments, individual factors, and income within your group.

Your payoff from the experiment At the end of the 32nd round of the experiment, we will randomly determine one of the rounds 1 to 32 ; each round will be selected with equal probabilities. Only the randomly selected round determines your payoff: your income from the experiment equals your income in the randomly selected round, converted to Euros.

Summary At the beginning of each round we inform you about the two possible values of your individual factor, and you have to choose either rule $A, B$, or $C{ }^{27}$

- Under rule $A$ we sum up the projects' profits of all persons who have chosen

\footnotetext{
${ }^{26} \mathrm{NI}$ : At the beginning of each round you have to choose a rule. Please consider that you have to choose a rule before you know your individual factor. Only after you have chosen the rule, you will receive precise information about your individual factor. In addition, we inform you about the factors of all other persons opting for the same rule you have chosen. FI: At the beginning of each round we inform you about your individual factor and you have to choose a rule. Then we inform you about the factors of all other persons opting for the same rule you have chosen.

${ }^{27} \mathrm{NI}$ : At the beginning of each round you have to choose either rule $A, B$, or $C$, without knowing your individual factor. FI: At the beginning of each round we inform you about your individual factor, and you have to choose either rule $A, B$, or $C$.
} 
$A$, and divide the sum equally among the persons who have chosen $A$.

- Under rule $B$ we sum up the projects' profits of all persons who have chosen $B$, and divide the sum according to the share of your investment in the sum of all investments under rule $B$.

- Under rule $C$ your income of the project equals your project's profits.

Then you learn your individual factor and determine your investment into the project. $^{28}$ Your income in the round equals your income from the project plus the rest of the endowment you did not invest into the project.

Before we proceed with the experiment, all participants have to answer some control questions on the computer screen. The control questions will help you to understand the rules of the game. The computer will correct the questions. As soon as all participants have completed the questions correctly, the experiment starts.

Do you have any further questions? Please contact us now!

${ }^{28} \mathrm{NI}$ : Then you learn your individual factor and determine your investment into the project. FI: Then you determine your investment into the project. 